\title{
LA AUTONOMIA LOCAL EN EL MARCO JURIDICO-INTERNACIONAL EUROPEO
}

\author{
POR \\ Albert Galinsoga Jordá \\ Profesor titular de Derecho Internacional Público \\ Antonio Blanc Altemir \\ Profesor asociado de Derecho Internacional Público \\ Antonio Novell Fabregat \\ Profesor colaborador de Derecho Internacional Público
}

\begin{abstract}
SUMARIO: I. La CARTA EuRopea de la Autonomía local: 1. Antecedentes y proceso de elaboración. 2. Formalización y estructura juridica de la Carta. 3. Los principios de la Carta.-II. Asociaciones INTERNACIONALES DE POderes LoCales Y Regionales: 1. Asociaciones de ámbito europeo: A) El Consejo de Municipios y Regiones de Europa (CCRE). B) La Asociación de Regiones Fronterizas Europeas (ARFE). C) La Conferencia de Regiones Periféricas Marítimas de la Comunidad Europea (CRPM). D) El Consejo de las Regiones de Europa (CRE). 2. Asociaciones de ámbito mundial: A: La Unión Internacional de Ciudades y Poderes Locales (IULA). B) La Unión Internacional de Alcaldes (UIM). C) La Federación Mundial de Ciudades Unidas (FMVJ).-III. LA Conferencia DE Poderes Locales Y Regionales de Eurofa (CPLRE): 1. Proceso de creación. 2. Objetivos y composición. 3. Funcionamiento. 4. Estructura y órganos. 5. Relaciones con otras instituciones.-CoNsIDERACIONES FINALES.
\end{abstract}

Con la firma en Strasbourg el 15 de octubre de 1985 de la Carta Europea de la Autonomía Local, el Gobierno español culminaba la primera fase de un proyecto de ámbito europeo del que -según manifestaba el ministro de Administración Territorial, Félix Pons (1)habia sido un decidido impulsor.

Este apoyo se manifestó tanto respecto del contenido de la Carta como de su formalización jurídica por la vía de un convenio obligatorio. Igualmente se plasma dicha voluntad política en la adopción de la Ley de 2 de abril de 1985, reguladora de las Bases del Régimen Local, que aun siendo anterior a la apertura a la firma de la Carta incorpora claramente los principios de la misma. Actitud que mantuvo su continuidad con la remisión del texto del convenio a las Cortes para su ratificación decidida por el Consejo de Ministros en su reunión de 15 de mayo de 1987.

De hecho, la Carta responde, como se apuntaba en el proyecto de la CPLRE de 1981, a la necesidad «de un texto oficial europeo que defina los principios comunes de la autonomía local». Necesidad que, por otra parte, habia sido reiteradamente manifestada en los diversos

(1) Presentación de la traducción oficial española de la Carta, editada por el Instituto de Estudios de Administración Local, Ministerio de Administración Territorial, Madrid, 1985. 
foros internacionales en que los poderes locales y regionales se hallan representados en cuanto tales.

El marco de las «IV Jornades Jurídiques de la Facultat de Dret del Estudi General de Lleida», dedicadas al estudio y debate del Régimen Local, sugiere una aproximación al tema desde la perspectiva iusinternacionalista. Partiendo del análisis jurídico de la Carta, se aborda el estudio del asociacionismo internacional de poderes locales y regionales y la institucionalización que ha recibido en el seno del Consejo de Europa, destacando la influencia que han desplegado en la protección de los intereses de las colectividades territoriales infraestatales en general y en la adopción de la Carta en particular.

\section{LA CARTA EUROPEA DE LA AUTONOMIA LOCAL}

Desde que en 1953 los «Estados Generales» del Consejo de Municipios de Europa (CCE) proclamara en Versailles la «Carta Europea de las Libertades Municipales» tanto las asociaciones de poderes locales como las instituciones del Consejo de Europa han perseguido la obtención de un texto normativo que estableciera unos principios y reglas comunes a nivel europeo occidental para el respeto de un «standard minimum» del derecho de autogobierno de las colectividades locales.

Tras un proceso marcado por la iniciativa de la Conferencia Permanente de Poderes Locales y Regionales del Consejo de Europa, finalmente el proyecto de una «Carta Europea de la Autonomía Local» obtuvo el plácet gubernamental al abrirse a la firma de los Estados miembros el Convenio que culminaba su proceso de elaboración y negociación en Strasbourg el 15 de octubre de 1985.

\section{ANTECEDENTES Y PROCESO DE ELABORACIÓN}

La iniciativa de 1953 respondía a una reacción de una amplia reunión de cargos electos a nivel local frente a la situación que sufrieron dichas colectividades a consecuencia de los regímenes totalitarios que desencadenaron la Segunda Guerra Mundial. El texto adoptado en aquella ocasión constituía una rotunda declaración de principios democráticos que obtuvo la rápida adhesión de millares de municipios de toda Europa.

La autonomía local, como fundamento básico de un régimen democrático; había recibido una formulación actualizada en el contexto de la inmediata postguerra en la obra de GASSER (2), que tuvo

(2) GASSER, A.: L'autonomie communale et la reconstruction de l'Europe, 1946. Se trata de una nueva evocación y adaptación de una concepción que ya había sido plasmada por Alexis de 
una amplia repercusión en el movimiento de asociación de municipios y entidades locales europeas en organizaciones no gubernamentales.

La propia creación de la Conferencia Europea de Poderes Locales, que se reunió por primera vez en enero de 1957 en el seno del Consejo de Europa, puede presentarse fundadamente como el reconocimiento a nivel intergubernamental del clima y el movimiento suscitado en torno a las ideas y aspiraciones antes mencionadas.

No obstante, no fue sino hasta 1968 que la Conferencia de Poderes Locales -hasta 1975 no se incorporó en su seno una representación de las instituciones regionales- planteó ante el Comité de Ministros del Consejo de Europa la adopción por éste de una Declaración de Principios sobre la Autonomía Local. La Resolución 64 (1968) formulaba dichos principios e invitaba al Comité de Ministros a hacerla suya. En este empeño obtuvo el respaldo de la Asamblea Parlamentaria que, por medio de su Recomendación 615 (1970) la transmitió al Comité de Ministros. El texto tenía su fundamento en la Resolución de la Conferencia y había recibido una nueva redacción efectuada conjuntamente por ambos órganos.

El Comité de Ministros, sin embargo, no procedió a la adopción de la Declaración propuesta. Las causas del rechazo parecen tener su explicación en el nivel de exigencias planteado en la misma. Como ha señalado uno de los más directos protagonistas en el proceso de elaboración de la Carta, L. Harmegnies, si bien parecía darse un acuerdo generalizado sobre los principios proclamados en la misma, los Gobiernos se mostraron reticentes en cuanto al tono excesivamente rotundo y pormenorizado de su redacción. Esta lectura se deduce claramente del siguiente párrafo de la respuesta que los delegados de los ministros dieron a la Asamblea:

«El Comité de Ministros reconoce que las colectividades locales deben jugar, en tanto que unidades de base de la sociedad, un papel esencial en la vida de las comunidades nacionales europeas. El Comité de Ministros, sin embargo, debe tener en cuenta las diferencias notables que presentan las estructuras constitucionales, jurídicas y administrativas de los diversos Estados miembros del Consejo de Europa. En el momento actual, estas diferencias no parecen permitir la adopción de una Declaración de principios sobre la autonomía local que sea aceptable para todos, como desearia la Asamblea (3).»

Tocqueville en estas enardecidas palabras: «Es... en el municipio donde reside la fuerza de los pueblos libres. Las instituciones municipales son a la libertad lo que las escuelas a la ciencia: La sitúan al alcance del pueblo, le hacen probar su uso pacifico y lo habitúan a servirse de ella. Sin instituciones municipales, una nación puede darse un gobierno libre, pero no posee el espiritu de la libertad.»

(3) Reproducida en CONSEIL DE L'EUROPE-CPLRE: «Rapport sur les Principes de l'Autonomie Locale», de 21 de septiembre de 1981. Doc. n. CPL (16) 6, p. 7. L. Harmegnies fue, en primer lugar 
La posición del Comité de Ministros se tradujo en una paralización de la iniciativa hasta 1979 , año en que -desbordada la idoneidad de una Declaración- la Conferencia se dirigió a elaborar el proyecto de la Carta, remitiendo una encuesta muy completa sobre el estado de la autonomía local en los distintos Estados miembros. A finales del mismo año, el ponente, señor L. Harmegnies, disponía de las respuestas de trece asociaciones nacionales y delegados individuales. Pese a las limitaciones de dicho material de trabajo -notables diferencias de planteamiento y falta de respuesta de más de la mitad de los Estados miembros-, se constituyó una Comisión compuesta por un grupo de expertos bajo la presidencia del «Rapporteur», que contribuyó eficazmente a la elaboración del proyecto. El texto, una vez ultimado, fue presentado ante la Comisión de Estructuras y Finanzas Locales de la CPLRE en junio de 1981. Paralelamente se sometió -sin menoscabo de la perspectiva global europea- a la consideración y matices que pudieran aportarse a escala nacional a través de las asociaciones de colectividades locales de ámbito nacional. El examen por parte de la Comisión de Estructuras Finanzas Locales se produjo tras una nueva revisión por parte del grupo de expertos, a tenor de las respuestas e impresiones recibidas (4).

El proyecto fue aprobado por la Resolución 126 (1981) en la 16. ${ }^{\mathrm{a}}$ sesión de la CPLRE, celebrada los días 27-29 de octubre, con la propuesta de su adopción en tanto que convenio europeo.

El procedimiento previsto en el texto estatutario de la CPLRE establece la remisión del proyecto a la Asamblea Parlamentaria para que ésta emita su dictamen y su posterior sumisión al Comité de Ministros para la adopción de la decisión. Sin embargo, la celebración de la 5. ${ }^{\mathrm{a}}$ Conferencia de Ministros Europeos responsables de las colectividades locales en Lugano, en octubre de 1982, permitió someter a su consideración el proyecto de Carta. Esta propuesta, formulada por la propia CPLRE, fue aceptada por el Comité de Ministros y permitió el examen y discusión de la Carta a nivel intergubernamental.

Los ministros reunidos en Lugano concluyeron que, si bien el proyecto de Carta constituía un paso importante hacia la definición de los principios de la autonomía local, se habían constatado reticencias relativas a dos aspectos: la necesidad de dar al texto la forma de un convenio vinculante para las partes, y ciertas disposicio-

(1968) ministro de Bélgica responsable de las Colectividades Locales y, posteriormente, desempeñó la presidencia de la Comisión que redactó el proyecto que sirvió de texto de trabajo para la elaboración de la Carta, en su calidad de ponente del informe que se acaba de mencionar.

(4) Las asociaciones noruegas y danesas habian planteado ciertas objeciones de fondo al primer texto, cuya motivación puede atribuirse a la ausencia de expertos nórdicos en el grupo de trabajo. Las adaptaciones introducidas en la redacción revisada comportaron su aceptación por parte de dichas asociaciones. 
nes inscritas en su contenido normativo dificilmente compatibles con algunos ordenamientos nacionales. En consideración a dichas reticencias y a la aceptacion generalizada de los principios vertebradores del texto, en Lugano se decidió solicitar al Comité de Ministros del Consejo de Europa, que encargará al órgano intergubernamental subsidiario para estas materias -el Comité Director para las cuestiones Regionales y Municipales (CDRM)- la adaptación del proyecto de Carta en contacto con la CPLRE, a tenor de las conclusiones de la Conferencia de Ministros (5).

Ante lo que se evidenciaba como una revisión del texto a la baja, tanto en cuanto a su rango normativo como en cuanto al contenido de sus disposiciones, la Asamblea Parlamentaria aportó un inequívoco apoyo tanto al proyecto como al propio protagonismo de la CPLRE, que en las conclusiones de Lugano quedaba relegada a desempeñar una función consultiva del CDRM. Dicha función consultiva podia estimarse de escasa entidad a tenor de la expresión «en contacto», que no garantizaba ni la participación de la CPLRE en los trabajos de redacción ni la consulta obligatoria, aunque no vinculante. Este posicionamiento de la Asamblea se concretaba en sus recomendaciones al Comité de Ministros:

a) Aprobar la Carta siguiendo el proyecto de la CPLRE.

b) Actuar de manera que la Carta tenga un carácter obligatorio en la forma de un convenio europeo.

c) Invitar a la $6 .^{\text {a }}$ Conferencia de Ministros a examinar la Carta con la voluntad de llegar a la adopción de un convenio, y

d) Solicitar el dictamen de la Asamblea antes de la adopción definitiva de dicho texto (6).

Posiblemente la enérgica posición de la Asamblea comportó el método seguido para la revisión del proyecto, puesto que la redacción se efectuó conjuntamente por la CPLRE y el CDRM. El texto resultante se sometió a la consideración de la $6 .^{\mathrm{a}}$ Conferencia de Ministros, celebrada en Roma en noviembre de 1984.

El informe político sobre el proyecto quedó bajo la responsabilidad de Oscar Luigi Scalfaro, ministro del Interior de Italia, quien se posicionó decididamente por su adopción (7).

El proyecto fue aceptado por los ministros, registrando un unánime consenso respecto a los principios y enunciados de la Carta y el

(5) Vid. CONSEIL DE L'EUROPE: «Rapport de la commission de l'aménagement du territoire et des pouvoirs locaux relatif aux résultats de la 5 . $^{\mathrm{e}}$ Conférence des Ministres européens responsables des collectivités locales» (Doc. 5.012).

(6) Recomendación 960 (1983), adoptada por la Asamblea el 25 de enero de 1983.

(7) Vid. CONSEIL DE L'EuROPE: Conférence des Ministres européens responsables des collectivités locales, «Projet de Charte Européenne de l'autonomie locale -rapport politique», Doc. n. MCL-6 (84) l-F, de 12 de octubre de 1984.

REVISTA DE ESTUDIOS.-7 
pronunciamiento favorable mayoritario respecto de su formalización por via convencional.

El proceso de elaboración se dio por concluido, adoptando el texto del Comité de Ministros del Consejo de Europa el 27 de junio de 1985, y estableciendo que el convenio quedaría abierto a la firma de los Estados miembros el 15 de octubre de 1985 con motivo de la celebración de la 20 Sesión Plenaria de la CPLRE.

\section{Formalización y ESTRUCTURA JURÍdica de LA CARTA}

En cuanto a su formalización jurídico-internacional, el texto europeo sobre los principios de la autonomía local conoció -como ha quedado evidenciado en lo anteriormente descrito- dos etapas: la primera tendente a su formulación en forma de Declaración adoptada por el Comité de Ministros del Consejo de Europa. La segunda y definitiva dirigida a su formalización por medio de un convenio abierto a la firma y ratificación de los Estados miembros.

La primera posibilidad reunía las ventajas e inconvenientes propios del «soft law» (8) y más específicamente del carácter y efectos propios de las resoluciones de las organizaciones internacionales (9): por una parte, la posibilidad de establecer un texto que reuniera una proclamación de principios de carácter declarativo, asumiendo la práctica generalizada de los Estados miembros en materia de autonomia local. Por otra, la de formular una serie de «desiderata» en forma de modelo o propuesta de «lege ferenda» que constituyera un punto de. referencia hacia el que la mayoría de los Estados miembros debieran ajustar su legislación.

El indudable valor de esta clase de textos ha sido destacado por eminentes iusinternacionalistas, especialmente en el sentido de eludir la valoración de los instrumentos jurídicos internacionales por criterios estrictamente formales. Como señala BAXTER (10), mientras

(8) Sobre el concepto -aún cargado de ambigūedades doctrinales-, vid. SEIDL-HoHENVELDERN: «International Economic "Soft Law"», RCADI, 1979, vol. 173, pp. 165-246; DUPUY, RENE JEAN: «Droit déclaratoire et droit programatique: de la couteme sauvage à la "soft law"», in $A F D I$, L'élaboration du droit international public (Colloque de Toulouse), Dalloz, Paris, 1975, pp. 132-148; Juste RuIz, J.: «Derecho Internacional Público y Medio Ambiente», ponencia escrita presentada a las VIII Jornadas de la Asociación de Profesores de Derecho Internacional y Relaciones Internacionales, in Problemas Internacionales del Medio Ambiente, Universidad Autónoma de Barcelona, 1984, pp. 5 y ss.; GolD, JosEPH: «Strengthening the Soft International Law of Schange Arrangments», $A J I L, 1983$, vol. 77, núm. 3, pp. 443 y ss.; WeIL, Prosper: «Towards Relative Normativity in International Laws, $A J I L, 1983$, vol. 77, pp. 413-442.

(9) Sobre el valor de dichos textos normativos internacionales, vid. CAstañeda, JoRGE: «Valeur juridique des résolutions des Nations Unies», $R C A D I, 1970$, vol. 129, pp. 205-332; VIRALlY, M.: «La valeur juridique des recommendations des Organisations Internationales», $A F D I$, 1956, pp. 81 y ss.

(10) BAXTER, R. R.: «International Law in "Her Infinite variety"», ICLQ, vol. 29, oct. 1980, núm. 3, p. 549 . 
instrumentos del mayor rango normativo, como los tratados internacionales, contienen cláusulas de contenido ambiguo y dudosa exigibilidad, otros que pueden calificarse de «fuentes informales», como los códigos internacionales de conducta adoptados por Resoluciones de Organizaciones Internacionales o determinados «Gentlemen's Agreements» concluidos en el marco del GATT, establecen estipulaciones precisas que despliegan efectos muy significativos en la práctica internacional.

Sin embargo, estos instrumentos internacionales de menor rango normativo parecen idóneos cuando se dirigen a regular la conducta de sujetos internacionales en un marco universal caracterizado por su diversidad y heterogeneidad. En el marco del Consejo de Europa es muy discutible la eficacia jurídica de este tipo de instrumento cuando no se trata de la regulación de materias -como el impacto de las nuevas tecnologias, por ejemplo-, que carecen de un lapso de tiempo suficiente para asentar la práctica de los Estados miembros y sus repercusiones internacionales. No es este el caso de los principios de la autonomía local, puesto que los Estados miembros reúnen en su conjunto lo que en el propio «Rapport» oficial se calificaba como «una tradición preciosa» (11). Si la materia a regular se presenta como una tradición bien asentada en la mayor parte de los Estados miembros, no menor es el grado de homogeneidad que se da respecto de una amplia mayoría de los Estados miembros en cuanto a los principios de la democracia parlamentaria y su contenido social. Esta homogeneidad ha dado lugar a un verdadero sistema europeo de protección de los derechos humanos -en su más amplia acepción- que se ha plasmado a nivel normativo en un conjunto de convenios, cuyo epicentro cabe situar en torno al Convenio de Roma de 1950 (12).

Una vez decidida la opción por la vía convencional, la CPLRE consideró dos posibles alternativas. La primera se concretaba en la posibilidad de adopción del texto en forma de protocolo adicional al Convenio Europeo para la protección de los Derechos del Hombre y las Libertades Fundamentales. Sin embargo, el carácter individual de los derechos civiles y políticos protegidos por dicho instrumento y el diseño de los mecanismos de garantía en él establecidos no se ajustaba con el carácter colectivo de un beneficiario como las colectividades locales.

La solución que se impuso fue la de la adopción de una Carta Europea independiente, inspirada en el modelo de la Carta Social. El reconocimiento de unos derechos económicos sociales que ésta

(11) CONSEIL DE L'EUROPE, CPLRE: «Rapport sur les principes...», doc. cit., p. 6.

(12) Para una visión de conjunto sobre la vigencia de este entramado puede verse: CouncIL OF EUROPE: Chart Showing signatures and ratifications of Conventions and Agreements Concluded within the Council of Europe, Strasbourg, 1-1-1987. 
efectúa se presenta diferenciado de los de carácter civil y político, y comporta, a su vez, el establecimiento de un procedimiento de aplicación y control independiente. El paralelismo trazado respecto a la Carta Social presentaba, no obstante, una serie de dificultades que se manifiestan en notables limitaciones que presenta el instrumento sobre autonomía local respecto de aquélla.

Así, aunque se adopta el sistema del «noyau obligatoire» al igual que en la Carta Social, el procedimiento de control de aplicación es mucho más endeble que el establecido en el instrumento social, limitándose, de hecho, a un púdico «follow up» establecido por el artículo 14. Aunque ambos aspectos merecen un comentario más amplio, cabe destacar lo siguiente:

- El «noyau obligatoire» se establece en torno a 14 principios básicos enunciados en distintos artículos y párrafos de artículos, de manera similar a lo establecido en la Carta Social Europea. Las Partes deben adherirse a un mínimo de 20 artículos y párrafos de artículos, entre los cuales 10 -como mínimo- deben pertenecer al núcleo de los 14 principios básicos. Este sistema se dirige a conciliar la diversidad que registran los sistemas jurídicos nacionales de los Estados miembros con un «standard minimum» a nivel de conjunto. La voluntad de elevar, en la medida de lo posible, dicho «standard» queda patentizada en la posibilidad de que las Partes puedan adquirir nuevas obligaciones respecto de artículos y párrafos de artículos que inicialmente no habian suscrito. Se prevé, pues, expresamente, que los Estados Parte adquieran dichas obligaciones en la medida en que dicha posibilidad esté a su alcance, una vez notificada esta voluntad al Secretario General. El primer día del mes siguiente a la expiración de un periodo de tres meses, contados a partir de la notificación, se considerará que dichas obligaciones forman parte integrante de la ratificación, aceptación o aprobación del Estado interesado.

- El procedimiento de control de aplicación se aparta sustancialmente del modelo de la Carta Social, y mucho más aún de las garantias jurisdiccionales que establece el Convenio sobre derechos humanos. Inicialmente se había previsto un mecanismo de control político similar al de la Carta Social en base a informes regularmente transmitidos por los Gobiernos. Su examen comportaría la participación de la CPLRE, e incluso la toma en consideración de las opiniones sostenidas por las asociaciones nacionales de colectividades locales. El dictamen de la Asamblea Parlamentaria cerraría el dispositivo de control institucional, cuyo carácter estrictamente político no estaría privado de ciertos efectos jurídicos al ser invocados sus resultados, por ejemplo, ante las jurisdicciones nacionales por las Corporaciones locales en el marco de sus litigios con los Gobiernos respectivos. 
El procedimiento finalmente adoptado consiste en la previsión del artículo 14, que obliga a las Partes Contratantes a comunicar al Secretario General del Consejo de Europa toda información apropiada relativa a las disposiciones legislativas y otras medidas adoptadas con el fin de adaptarse a los términos de la Carta. Las limitaciones de este procedimiento son evidentes. Por una parte no se establece un órgano específico para efectuar el control de aplicación (13). Por otra, la obligación de comunicar la información pertinente se refiere a las medidas (legislativas o de otro tipo) adoptadas por los Estados miembros «con el fin de adaptarse a los términos» de la Carta. Esto significa, contrariamente a lo que parece interpretarse a partir del «Informe explicativo» oficial (14), que la obligación de los Estados Partes no se dirige a comunicar toda medida que pueda afectar a la autonomía local, y más especialmente aquellas susceptibles de comportar un incumplimiento de sus principios, sino las emprendidas para adaptarse a la misma.

La justificación de semejantes limitaciones frente al sistema inicialmente previsto podría proporcionarla un argumento avanzado por el propio ponente señor Harmegnies (15), al indicar que frente a la Carta Social -que se dirige a garantizar derechos sociales y económicos subjetivos-, la autonomía local es una materia que afecta a las relaciones entre autoridades públicas y, por lo tanto, a la propia estructura del Estado. Esta constatación explicaría la sensibilidad gubernamental a admitir un procedimiento de control más estricto (16).

En cuanto a la firma, ratificación y entrada en vigor, la Carta establece una serie de disposiciones que constituyen ya cláusulas de estilo en los convenios elaborados en el marco del Consejo de Europa, exigiendo un mínimo de cuatro ratificaciones para la entrada en vigor.

(13) Podria haberse adjudicado dicha función a un órgano ya existente como la CPLRE o el CDRM o a uno de carácter mixto creado a partir de ambos. Un precedente favorable a esta última opción podria ser el resultado del trabajo conjunto de ambos órganos en la redacción final del proyecto de la Carta que fue aceptada por los Gobiernos de los Estados miembros.

(14) Concretamente nos referimos al párrafo que encabeza el comentario del artículo 14, cuyo tenor literal es el siguiente: «Este artículo está destinado a facilitar el control de la aplicación de la Carta en cada Parte, creando para ella la obligación de proporcionar toda información apropiada al secretario general del Consejo de Europa...; es particularmente importante que el secretario general pueda disponer de toda información concerniente a los cambios de legislación u otras medidas que puedan tener unas repercusiones importantes sobre la autonomia local, tal como está definida en la Carta) (CONSEIL DE L'EUROPE: Rapport explicatif sur la Charte européenne de l'autonomie locale, Strasbourg, 1986, p. 20. El subrayado es nuestro).

(15) CoNSEIl DE L'EUROPE, CPLRE: «Rapport sur les principes...», Doc. cit., p. 12.

(16) Para un análisis más detallado, vid. GALETTE, ALFONS: «The Draft European Charter of Local Self Governement by The Conference of Local and Regional Powen, GYIL, vol. 25, 1982, páginas 228 y ss. 


\section{LOS PRINCIPIOS DE LA CARTA}

Un análisis del contenido normativo de la Carta permite vertebrar un haz de principios y normas a partir de dos reglas básicas: autonomía local y legitimidad democrática. La estrecha relación e interdependencia de ambos principios constituyen una base equilibrada sobre la que se pone en común la experiencia y la tradición de los Estados miembros. El equilibrio entre ambos principios se produce de manera similar al significado y valor del signo conocido como «doble implicación» en el lenguaje formal de la lógica matemática. Su traducción verbal puede darse en los siguientes términos «sí y sólo sí». Es decir, según el artículo 3, párrafo 1:

«Por autonomia local se entiende el derecho y la capacidad efectiva de las Corporaciones locales de ordenar y gestionar una parte importante de los asuntos públicos en el marco de la Ley, bajo su propia responsabilidad y en beneficio de sus habitantes.»

Pero ese derecho sólo puede tener una titularidad y un ejercicio basados en la legitimidad democrática de las autoridades beneficiarias:

«Este derecho se ejerce por Asambleảs o Consejo integrados por miembros elegidos por sufragio libre, secreto, igual, directo y universal y que pueden disponer de órganos ejecutivos responsables ante ellos mismos. Esta disposición no excluye el recurso a las asambleas de ciudadanos, al referéndum o a cualquier otra forma de participación directa de los ciudadanos alli donde esté permitido por la Ley» (art. 3, párrafo 2).

Por otra parte, la legitimidad democrática de los poderes locales es el fundamento de la atribución del derecho a la autonomia. De manera que el derecho que se desea reconocer no puede negarse a aquellas Corporaciones locales que reúnan estos requisitos.

El contraste entre ambos principios en el ámbito de la doctrina iusinternacionalista presenta un alcance muy desigual. La legitimidad democrática ha sido analizada en marcos tan diversos como el reconocimiento de Gobiernos y la protección de los derechos humanos, mientras que la noción de autonomia en su dimensión local se presenta como un objeto prácticamente inexplorado (17).

(17) Como un discutido corolario del principio de la libre determinación de los pueblos pueden mencionarse recientemente interesantes incursiones como las de LAPIDOTH, RUTH: «Some reflections on Autonomyn, in Mélanges offert a Paul Reuter, le droit international: unité et diversité, Pedone, Paris, 1981, pp. 389-399; Hannum, H. y Lillich, R. B.: «The Concept of Autonomy in 
Tampoco han recibido excesiva atención aspectos concretos vinculados a la misma, como los relativos a la cooperación transfronteriza o la conclusión de acuerdos a nivel infragubernamental (18).

Con los riesgos que ello comporta, no parece descabellado imbricar la noción de autonomía local en una zona intermedia compartida por el ámbito de aplicación de dos principios fundamentales del Derecho Internacional contemporáneo: el respeto de los derechos humanos en su dimensión civil y política colectiva, por una parte, y la libre determinación de los pueblos como fundamento de toda organización política, por otra. Esta última consideración se formuló en el informe político presentado ante las Conferencias de Ministros europeos responsables de las Colectividades Locales por parte de los ponentes de Lugano, el consejero nacional suizo (señor Dupont), y Roma, el ministro del Interior italiano (señor Scalfaro). Este último, retomando la palabra de su antecesor, decia:

«...Innumerables ciudadanos europeos han tomado conciencia del hecho que en el primer rango de la historia de las libertades fundamentales de las que permanecen inseparables se encuentran las libertades locales, municipales y regionales, expresión del derecho de los pueblos a gobernarse por sí mismo, a disponer de sí mismos; por tanto, a administrarse a sî mismos (19).»

La autonomía local aparece, pues, en el punto de intersección del ámbito de aplicación de ambos principios y parece indudable -en el marco regional europeo- que forma parte de los Principios Generales del Derecho comunes a los ordenamientos jurídicos de una mayoria muy significativa de los Estados miembros del Consejo de Europa. Su internacionalización y formulación por la vía convencional ofrece, de este modo, un instrumento adecuado para el establecimiento de un standard que favorezca el proceso de construcción de la unidad europea.

El carácter central del principio de la autonomía local se asegura por medio del artículo 2, que establece su reconocimiento en la legislación estatal y, en la medida de lo posible, en la Constitución.

International Law», $A J I L, 1980$, vol. 74, pp. 858-889; SoHN, L. B.: «The Concept of Autonomy in International Law and the Practique of the United Nations", ILR, vol. 15, 1980, pp. 180-190, aunque siempre respecto a colectividades susceptibles de encuadrarse en el marco conceptual de las minorias nacionales o asimiladas (religiosas, lingūisticas, raciales, etc.)

(18) En este sentido, vid. BuRdeAu, Geneviève: «Les accords conclus entre autorités administratives ou organismes publics de pays différents"), in Mélanges offerts a Paul Reuter..., op. cit., pp.103-126, o DUPUY, PIERRE MARIE: «La cooéeration régionales tranfrontalière et le droit international», $A F D I, 1977$, pp. 837-860.

(19 CONSEIL DE L'EuROPE: «Conference des Ministres Européens responsables...», Doc. cit., p. 2. 
El proyecto establecía el reconocimiento necesariamente a nivel constitucional, pero su mantenimiento en este nivel de exigencia hubiera comportado automáticamente dificultades de asunción para ciertos Estados miembros por razones diversas, como, por ejemplo, en el caso británico, dadas sus peculiaridades constitucionales, o en el de Estados de estructura federal, como Suiza, en que la administración local se rige por la constitucional cantonal. Pese a que el proyecto de la CPLRE ya había tenido en cuenta esta cuestión y se habían definido por una fórmula flexible («constitucionalmente» por «en la Constitución»), dicha propuesta no fue adoptada en el texto definitivo.

El principio se concreta en una serie de normas básicas que también se inspiran en reglas derivadas de la autonomía local a nivel más general. Nos referimos a los principios de descentralización y de subsidiariedad. Respecto del primero recibe su expresión normativa en el artículo 4, párrafo 3, que establece:

«El ejercicio de las responsabilidades públicas debe, de modo general, incumbir preferentemente a las autoridades más cercanas a los ciudadanos.»

El límite a su alcance lo aporta la frase siguiente:

«La atribución de una responsabilidad a otra autoridad debe tener en cuenta la amplitud o la naturaleza de la tarea o las necesidades de eficacia o economí.»

Si se contraste esta última frase con la correspondiente del proyecto de la CPLRE, puede observarse una sustancial amplitud en cuanto a los supuestos limitativos del principio y una ambigüedad muy considerable en favor de las autoridades gubernamentales en el texto definitivo frente a la redacción quizá excesivamente taxativa del proyecto (20).

El principio de subsidiariedad viene formulado en el párrafo anterior del mismo articulo:

(20) El proyecto formulaba de manera muy taxativa el principio de subsidiariedad como punto de partida. Así, una vez admitida ésta de manera general, dedicaba el párrafo siguiente al principio de descentralización, que jugaba únicamente entre autoridades locales, puesto que el conflicto de competencias con las gubernamentales ya quedaba resuelto gracias a la afirmación de la subsidiariedad en favor de las Corporaciones locales en su conjunto. La frase en cuestión establecía: «Las colectividades locales de nivel superior sólo deben asumir una tarea, o recibir la atribución de una responsabilidad por la ley, en la medida en que sea necesario por el hecho del alcance de la tarea, o cuando las colectividades locales de base no puedan cumplirla de manera eficazs (artículo 3, párrafo iii, del proyecto). Como se verá, la revisión a la baja del texto del proyecto ha alterado su estructura lógica, por lo que hubiera procedido la reordenación de los párrafos, dando prioridad a la formulación del principio de descentralización frente al de subsidiariedad. 
«Las Corporaciones locales tienen, dentro del ámbito de la Ley, libertad plena para ejercer su iniciativa en toda materia que no esté excluida de su competencia o atribuida a otra autoridad» (art. 4, párrafo 2).

La eliminación de la exigencia de una atribución explícita a otra autoridad es el cambio más significativo respecto del proyecto.

El texto definitivo parece presentar una seria deficiencia al mantener el orden del proyecto. El contenido final de estas disposiciones sugiere la presentación del principio de subsidiariedad como una consecuencia del principio de descentralización y no a la inversa, como podría deducirse de la ordenación definitiva de ambos principios. Si se acepta esta premisa, sorprende el distinto trato recibido por ambos principios, puesto que mientras el de subsidiariedad forma parte del núcleo de 14 reglas del «noyau obligatoire», el de descentralización carece de esta consideración.

Hecha esta observación sobre un fenómeno nada infrecuente en instrumentos internacionales adoptados tras una negociación en foros diplomáticos, como las Conferencias de Ministros responsables de las Colectividades locales, cabe enunciar, de manera muy sucinta, algunas de las consecuencias normativas que se derivan de la articulación de la autonomía local en torno a estas dos reglas principales.

Las consecuencias de la autonomía local se refieren al carácter pleno y completo de las competencias encomendadas a las Corporaciones locales, el derecho de adaptación a las condiciones para el ejercicio de competencias delegadas y el de consulta -en la medida de lo posible- a su debido tiempo y de forma apropiada durante el proceso de planificación y decisión de todas aquellas cuestiones que les afecten directamente (párrafos 4, 5 y 6 del art. 4) (21).

La protección de los límites territoriales de las Corporaciones locales formulada por el artículo 5 establece que para cualquier modificación de los mismos deberá efectuarse previa consulta por vía de referéndum en el ámbito de las mismas siempre que la legislación lo permita (22). Esta disposición forma parte del conjunto de 14 principios básicos en el esquema del «noyau obligatoire».

El artículo 6 se dirige a la adecuación de las estructuras y los medios administrativos a las funciones y competencias de las Corpo-

(21) La limitación descrita en la frase «en la medida de lo posible» no parece referirse al derecho de consulta en si mismo, sino a las modalidades del mismo enunciadas a continuación, que pueden verse afectadas por elementos como la urgencia (Vid. el «Rapport explicatif...), Doc., cit., p. 14.

(22) La expresión «alli donde la legislación lo permita» viene a recoger divergencias legislativas entre los Estados miembros. Así, por citar algunos ejemplos, mientras en Suiza algunas constituciones cantonales garantizan expresamente la existencia de los municipios, llegando, incluso, a enumerarlos, y establecen la via referendaria obligatoria o facultativa para cualquier modificación territorial, en otros Estados, como Bélgica o el Reino Unido, la fusión de colectividades locales u otras modificaciones quedan a la discreción del legislador. 
raciones locales. Forma, en este sentido, un bloque con el artículo siguiente, puesto que mientras el primero garantiza la capacidad de definir las estructuras internas y de adaptar a sus necesidades especificas, el artículo 7 plantea idénticos objetivos con respecto al estatuto de los cargos electos y a las condiciones de ejercicio de los mismos en materia de independencia respecto a otros poderes, compensación financiera y compatibilidades.

El control administrativo de los actos de las Corporaciones locales, regulado por el artículo 8 , sugiere una mayor atención debido a la importancia del mismo en la mayor parte de Estados miembros del Consejo de Europa. En la práctica comparada, éste es indudablemente uno de los recortes más sustanciales a la efectividad de la autonomía local (23). El lugar central de esta disposición lo ocupa el párraio 2, que, en su poca cuidada traducción oficial, establece:

«Todo control administrativo de los actos de las Corporaciones locales no debe normalmente tener como objetivo más que asegurar el respeto de la legalidad y de los principios constitucionales. El control administrativo puede, sin embargo, comprender un control de oportunidad ejercido por las autoridades de nivel superior en lo que concierne a las tareas cuya ejecución ha sido delegada a las Corporaciones locales.»

El principio enunciado parte de la distinción entre control de legalidad y control de oportunidad, admitiéndose el ejercicio residual de este último únicamente respecto del ejercicio de competencias delegadas. Se ha suprimido del texto del proyecto de la CPLRE la exigencia de una regulación constitucional o legal de los procedimientos de control aplicables a las Corporaciones locales.

En un plano similar cabe situar las previsiones del artículo 9 en materia de recursos financieros de las Corporaciones locales. Sus líneas maestras vienen diseñadas en los tres primeros párrafos -incluidos entre los 14 básicos de la Carta- que establecen el derecho a unos recursos propios suficientes, en el marco de la política económica nacional, la proporcionalidad de los mismos a las compe-

(23) En 1979, las asociaciones de municipios británicas presentaron un informe al Gobierno levantando acta de más de un millar de prácticas restrictivas diferenciadas. Entre las más usuales se apuntan:

Circulares gubernamentales que contienen dictámenes u opiniones denominadas por las asociaciones británicas como «consejos de abuela».

Solicitudes de reexamen de decisiones ya adoptadas por las colectividades locales.

Obligación jurídica de obtención de autorización previa a la actuación o la decisión.

Necesidad de confirmación para que las decisiones de las colectividades locales entren en vigor.

Derecho de anulación posterior, por diversos motivos, de las decisiones ya adoptadas.

"Tutela coercitiva» o «tutela de sustitución», que permite a las autoridades superiores, en ciertas circunstancias, ejecutar la ejecución de las disposiciones o el ejercicio de las funciones en lugar de las colectividades locales o, incluso, asegurar el conjunto de su gestión. 
tencias previstas por la Constitución a la Ley y la exigencia de su origen al menos parcial a partir de ingresos e impuestos locales fijados por las propias Corporaciones locales dentro de los límites de la Ley.

Otros principios complementarios en esta materia establecen la naturaleza diversificada de los sistemas financieros y su evolutividad en vista a la evolución real del coste del ejercicio de sus competencias (párrafo 4), la compensación financiera de las Corporaciones más débiles sin menoscabo de su autonomía efectiva (párrafo 5), la consulta sobre las modalidades de adjudicación de los recursos redistribuidos (párrafo 6) y la no asignación -en la medida de lo posible- de subvenciones supeditados a la realización de proyectos específicos (párrafo 7). El artículo se cierra con una cláusula no prevista en el proyecto que establece en favor de las Corporaciones locales el acceso al mercado nacional de capitales (párrafo 8).

El derecho de asociación de las Corporaciones locales se ve reconocido a diversos niveles en el artículo 10. En primer lugar se establece la cooperación y asociación entre Corporaciones para la realización de tareas comunes. Aunque el texto no lo explicita, cabe considerar que se refiere en el marco estatal. En segundo lugar se establece el derecho de integración en asociaciones de Corporaciones locales, tanto en el plano nacional como internacional. Es significativo que este último se reconoce sin restricciones y demanera taxativa. Más delicada es la interpretación del párrafo 3, que establece:

«Las Corporaciones locales pueden, en las condiciones eventualmente previstas por la Ley, cooperar con las Corporaciones de otros Estados.»

El proyecto de la CPLRE establecía la habilitación sin limitaciones -como las que pueden derivarse de la frase «en las condiciones eventualmente previstas por la Ley» y quizá con un exceso de audacia añadía lo siguiente: «tal como está previsto particularmente por el Convenio-marco Europeo sobre la Cooperación Transfronteriza de las Colectividades o Autoridades Locales». De este modo parecía vincularse -para aquellos Estados que fueran parte de la Carta y aceptaran obligarse por este párrafo- la obligatoriedad de dicho Conveniomarco (24).

La primera parte de la Carta concluye con el establecimiento de garantías jurisdiccionales en la legislación interna para que las

(24) Respecto de dicho Convenio-marco, existen serias reticencias por parte del Gobierno español a su ratificación, puesto que, como expresó el Ministro de Administraciones Públicas, Joaquin Almunia, en la IV Conferencia Europea de Regiones Fronterizas (Zaragoza, marzo de 1987), se supedita la misma a la conclusión de acuerdos interestatales que garanticen su eficacia. También expresó su preocupación cuando se cuestiona la responsabilidad del Estado en las relaciones internacionales. 
Colectividades Locales puedan hacer efectivo el libre ejercicio de sus competencias y el respeto de la autonomía local (art. 11).

En resumen, puede caracterizarse la Carta Europea de la Autonomía Local como un instrumento internacional llamado a desempeñar un papel relevante en el sistema regional europeo y en el marco de los objetivos del Consejo de Europa. Dos consideraciones pueden cerrar este breve análisis. La primera se refiere a la solidez y vigencia de los principios enunciados por el texto. Una observación detallista puede resaltar la concepción general desde la que han sido formulados: en ninguna de sus disposiciones califica de «atribuidas» las competencias, funciones y tareas propias de las Corporaciones locales, mientras que se utiliza este calificativo respecto de las de otras autoridades del nivel superior. Es decir, el texto implícitamente parte del «reconocimiento" de los principios de la autonomía local, calificando de competencias de atribución las encomendadas a otras autoridades. Parece partirse, pues, de una concepción similar al modelo de la Constitución italiana (25).

La segunda consideración se refiere inevitablemente a las limitaciones que el procedimiento de control previsto proyecta sobre su eficacia. Dificilmente pueden considerarse eficaces para la protección de la autonomía local las garantias que ofrece el artículo 14 en su actual redacción. Con todo, cabe esperar que en éste como en otros casos, en el ámbito jurídico internacional del Consejo de Europa, pueda posteriormente complementarse el procedimiento de información descrito por medio de un Protocolo adicional o instrumento anexo que refuerce la propia acción institucional de la CPLRE y las asociaciones en ella representadas y la especial sensibilidad que la Asamblea Parlamentaria ha manifestado respecto a este tema durante el curso de la elaboración de la Carta. En el texto actual la acción de estos órganos parece proporcionar un procedimiento de control mucho más eficaz que el establecido en la propia Carta.

\section{ASOCIACIONES INTERNACIONALES DE PODERES LOCALES Y REGIONALES}

La construcción de Europa no es tarea exclusiva de los Gobiernos. Aun reconociendo la importancia capital que éstos juegan en el proceso de unificación, a través de la cooperación diplomática, técnica y económica, es necesario recordar que Europa, aunque estructurada

(25) El articulo 5 establece que la República (...) reconoce y favorece las autonomías locales, realiza en los servicios que dependen del Estado la más amplia descentralización administrativa, adapta los principios y los métodos de su legislación a las necesidades de la autonomía y de la descentralización. En el mismo sentido, el artículo 1 de la Ley bávara sobre la administración local declara que los municipios «constituyen el fundamento del Estado». 
en Estados, está formada por más de 120.000 municipios y un millar de regiones que están llamados a desempeñar un protagonismo creciente en el proceso de construcción europea.

La asociación de los Estados constituye a menudo una tarea que se ve dificultada por los intereses nacionales, que pueden, incluso, aparecer como contrapuestos, mientras que los municipios y las regiones, cuyos problemas requieren soluciones similares en toda Europa, pueden constituir, a través de su interés en conjugar esfuerzos y en poner en común sus experiencias, instancias muy válidas y adecuadas para la unidad europea.

El fenómeno del asociacionismo internacional de municipios, que conoció un gran desarrollo tras la segunda guerra mundial, contribuyó de una manera notable a la reconcialición entre los Estados europeos de régimen democrático y al fomento de la cooperación entre los pueblos.

Partiendo de estos principios y de la labor iniciada ya unos años antes por algunas asociaciones internacionales de poderes locales, en particular el Consejo de Municipios de Europa (CCE), el Consejo de Europa creó en 1957 la Conferencia Europea de Poderes Locales, que se configuró como un foro internacional de participación de los representantes de dichos poderes en los asuntos auropeos, y que en 1975 pasó a llamarse Conferencia de Poderes Locales y Regionales de Europa (CPLRE).

En su seno tienen reconocido el estatuto de observador otras asociaciones internacionales de poderes locales y regionales, que actúan estrictamente en el ámbito europeo, como el Consejo de Municipios y Regiones de Europa (CCRE), la Asociación de Regiones Fronterizas Europeas (ARFE), la Conferencia de Regiones Periféricas Maritimas de la Comunidad Europea (CRPM) y el Consejo de las Regiones de Europa (CRE). Otras asociaciones internacionales que sobrepasan el ámbito europeo, aunque tienen una fuerte incidencia e implantación en el mismo, son: la Unión Internacional de Ciudades y Poderes Locales (IULA), la Unión Internacional de Alcaldes (UIM) y la Federación Mundial de Ciudades Unidas (FMVJ).

\section{De Ámbito EURopeo}

A) El Consejo de Municipios y Regiones de Europa (CCRE).

El nacimiento del Consejo de Municipios de Europa (CCE) fue producto de la acción entusiasta de un grupo de federalistas europeos, entre los que Serafini (26) destaca a Adolfo Gasser, que ya en 1934

(26) SERAFINI, U.: I gemellaggi, l'Europa dei cittadini e il sostegno attivo all Unione europea. Comuni Europa, febrero 1987, p. 1 . 
había fundado la «Unión Europea, movimiento suizo para la federación de Europa»; a JEAN BARETH, federalista francés, que había participado en el primer congreso de la «Unión Europea de Federalistas», celebrada en 1947, en la ciudad de Montreaux; a LADEBECK, que presidió en 1953 la comisión redactora de la «Carta europea de las libertades locales» (27), y a ADRIANo OLIVETTI, que ya en 1945 había expuesto magistralmemnte (28) las líneas básicas del pensamiento político autonomista y federalista.

El Consejo de Municipios de Europa fue creado en el año 1951, en Ginebra, con la voluntad de crear una Europa unida sobre las ruinas de la segunda guerra mundial y con la convicción de que los municipios constituyen el fundamento de la construcción europea (29). Esta idea está presente en el preámbulo de sus Estatutos al afirmar que el «Consejo debe llegar a ser una institución permanente de la organización europea», que se esforzará sin descanso en «ampliar las libertades de los municipios y las regiones y en trabajar por la construcción de una Europa unida basada en estas libertades»\%. En 1984, a petición de las autoridades regionales adheridas, el Consejo de Municipios de Europa paso a denominarse Consejo de Municipios y Regiones de Europa.

El Consejo reúne cerca de 30.000 colectividades locales y regionales (municipios, departamentos, provincias, kreise, distritos, condados, regiones..., adheridos sobre la base de una decisión de sus asambleas electas), a través de sus secciones nacionales en Austria, Bélgica, España, Francia, Grecia, Irlanda, Italia, Luxemburgo, Holanda, Portugal, República Federal de Alemania, Reino Unido y Suiza. El Consejo de Municipios y Regiones de Europa se dedica desde hace más de treinta años a defender las libertades locales, es decir, los derechos de los municipios, departamentos y regiones frente a los Estados centrales y a desarrollar el espíritu europeo, con el fin de promover una federación de Estados democráticos de Europa. Así, entre los fines del Consejo, el artículo 2 de sus estatutos menciona, junto al de «obtener, reforzar y defender la autonomía de sus municipios, regiones, colectividades locales y regionales», y «facilitar su gestión, asegurrar sus libertades y contribuir a su prosperidad...», el de «desarrollar el espiritu europeo en los municipios, regiones, colectividades locales y regionales, para promover una federación de Estados europeos basada en la autonomía de estas colectividades», y

(27) Presentada en los «Estados Generales de Versalles en 1953».

(28) Vid. a tal efecto, OLIVETrı, A.: L'ordino politico delle comunità, 1945.

(29) Idea que ya habia expuesto GASSER en su obra Die Gemeindefreitheit als Rettung Europas, Basilea, 1943, traducida al francés con el título L'autonomie comunale et la reconstruction de l'Europe, Neuchâtel, 1946. 
a tal efecto asegurar su participación y representación «en los organismos europeos e internacionales».

El Consejo de Municipios y Regiones de Europa está constituido en una federación de asociaciones nacionales que, en cuanto organizaciones autónomas, comprenden como miembros activos los municipios, las regiones, las colectividades locales y regionales, asi como a las asociaciones de poderes locales y regionales a título colectivo (30), pudiendo, según el artículo 3 de sus Estatutos, recibir igualmente la adhesión de organizaciones europeas como miembros asociados (31), siempre que contribuyan a la consecución de sus objetivos.

Los órganos del Consejo de Municipios y Regiones de Europa son, según el artículo 5, 3: la Asamblea de delegados, el Comité Director Europeo y el Comité de Presidencia.

La Asamblea está formada por los delegados de las asociaciones nacionales con un mínimo de siete representantes y un máximo de 19, según la población del Estado (32), y entre sus funciones destaca la de fijar las líneas políticas para alcanzar sus fines, designar los miembros del Comité Director Europeo a propuesta de las asociaciones nacionales y adoptar y modificar sus Estatutos.

El Comité Director Europeo, formado por cuatro miembros por cada sección nacional de los Estados con más de 20 millones de habitantes y por dos miembros por cada una de las demás, constituye el órgano ejecutivo del Consejo de Municipios y Regiones de Europa. Según el artículo 8 de sus Estatutos, el Comité planifica las actividades del Consejo de acuerdo con las líneas directrices fijadas por la Asamblea de delegados, aprueba los presupuestos, organiza el régimen financiero de la organización y elige al presidente europeo, a los vicepresidentes (33), al secretario general y demás cargos y, en general, ejerce todas las competencias que no están atribuidas expresamente a los demás órganos.

El Comité de Presidencia está formado por el presidente europeo, los vicepresidentes y el secretario general, asi como por dos delegados

(30) Las modalidades de adhesión y representación de miembros activos a dichas asociaciones nacionales que constituyen el Consejo de Municipios y Regiones de Europa se determinan, según el articulo 3 de sus Estatutos, por cada asociación nacional de conformidad con el derecho interno del Estado en cuestión.

(31) Como asociaciones europeas y nacionales de personal municipal, organizaciones que se ocupen del desarrollo regional, de actividades europeas, de la promoción del turismo intraeuropeo, etcétera.

(32) La distribución es, según el articulo 7 de sus Estatutos, la siguiente:

- Hasta 10 millones de habitantes, siete delegados.

- Hasta 20 millones de habitantes, 11 delegados.

- Más de 20 millones de habitantes, 19 delegados.

(33) El número de vicepresidentes no puede exceder de cinco y su mandato, al igual que el del presidente, es de dos años, pudiendo ser reelegidos (art. 13). 
por cada sección nacional de los Estados con más de 20 millones de habitantes y por uno por cada una de las demás (art. 10). Sus funciones son las que expresamente le delegue el Comité Director Europeo.

Es de destacar que los votos se confieren a título individual por todos los delegados votantes y no por delegaciones nacionales, adoptándose los acuerdos por mayoría de delegados presentes y votantes.

Las actividades del Consejo de Municipios y Regiones de Europa son numerosas y hacen referencia a los fines estatutarios del artículo 2. En este sentido, el Consejo organiza intercambios de experiencias relativas a los problemas fundamentales de la gestión municipal y regional a través de conferencias y coloquios europeos (34) y asegura la representación y la defensa de las colectividades locales y regionales en las instituciones europeas. En este sentido, el Consejo ha puesto en funcionamiento estructuras de representación y consulta de las colectividades locales y regionales tanto en la Comisión Europea, a través del Comité Consultivo de las Instituciones Locales y Regionales, como en el Parlamento Europeo mediante el Intergrupo de Electos Locales y Regionales y en el Consejo de Europa donde el Consejo de Municipios y Regiones de Europa anima, a través de sus delegados, la Conferencia de Poderes Locales y Regionales de Europa.

Otra de las actividades importantes del Consejo de Municipios y Regiones de Europa es el desarrollo del espíritu europeo a través de la promoción de los hermanamientos (jumelages). Ya en los principios de la década de los años 50, y, por lo tanto, coincidiendo con su nacimiento, el Consejo, partiendo de la convicción de que aquéllos constituyen el medio más concreto para trasladar la idea de Europa a la vida cotidiana de los pueblos, incluyó el desarrollo de los hermanamientos en Europa entre sus acciones prioritarias. Jean Bareth, uno de los fundadores del CCE, fue quien ideó el sistema de los hermanamientos, que definió como el encuentro de dos o más municipios que proclaman su asociación para actuar en una perspectiva europea, para afrontar sus problemas y para desarrollar entre ellas lazos de amistad cada vez más estrechos (35), y que pone de manifiesto la concurrencia de esfuerzos de los municipios interesados en la consecución de un propósito común de paz y prosperidad.

El Consejo de Municipios y Regiones de Europa estuvo, a través de la idea de Bareth, en el origen del amplio movimiento de

(34) Algunos de los llevados a cabo últimamente hacen referencia a «las colectividades locales frente a los problemas de la toxicomania», «la sociedad pluricultural a nivel local en Europa» y «los aeropuertos interregionales en Europas, entre otros.

(35) Vid., en este sentido, BARETH, J.: L'Europe des Communes. 
hermanamiento de municipios que constituye, sin duda, el caldo de cultivo ideal para el aprendizaje de la «ciudadania europea». El fin inmediato del sistema de hermanamiento radica en abrirse a los pueblos vecinos para conocerse mejor a través de la cultura, la lengua, la historia, fomentando la amistad y la cooperación, debatir conjuntamente las soluciones a problemas similares que presentan los pueblos y ciudades a través del intercambio de experiencias para llegar al fin mediato y último objetivo del sistema que radica en poner de manifiesto la pertenencia a una misma cultura y a una misma comunidad: la Comunidad Europea.

La historia del movimiento de los hermanamientos ha pasado según SERAFINI (36) por tres fases diferentes: La primera de ellas presenta la doble característica de la aparición del deseo de reconciliación entre los Estados europeos de régimen democrático (37) y de la nostalgia de una unidad europea, de corte federalista y no exclusivamente mercantilista. La segunda fase se caracteriza por haber desarrollado en plena guerra fria unos ideales pacifistas y de cooperación entre los pueblos, basados en la filosofia federalista que los inspira; y la tercera se encamina, una vez logradas la reconciliación europea, al protagonismo que debe jugar el movimiento de los hermanamientos en la construcción de una Europa de las regiones armoniosamente constituidas en una «auténtica, fraterna comunidad económica supranacional... una Europa que construya democráticamente un espacio social común... y que active con una política común, económica, social hacia el resto del mundo» (38).

La vitalidad del movimiento confirma hasta qué punto este tipo de intercambios ha llegado a formar parte de la vida cotidiana de las poblaciones hermanadas, constituyendo el mejor medio de toma de conciencia de la realidad europea y de soporte de la difusión del espíritu europeo. El movimiento ha tenido una amplia acogida desde sus orígenes: Europa cuenta en la actualidad con más de 5.000 municipios hermanados. La organización de los hermanamientos corre a cargo generalmente de un "Comité de Hermanamiento», que desarrolla un programa concreto de actividades: intercambios educativos, profesionales, culturales e incluso de carácter económico, que contribuyen al desarrollo del municipio o de la región.

El Consejo de Municipios y Regiones de Europa colabora con los municipios a encontrar su «partenaire» y les presta asistencia en todas

(36) Serafini, U., op. cit., pp. 2 y 3.

(37) En este sentido cabe destacar la gran repercusión que tuvo el hermanamiento, a principios de la década de los cincuenta, entre la ciudad de Boulogne-Billancourt y Neuköln, distrito de Berlin Oeste.

(38) Serafini. U. op. cit., p. 2.

REVISTA DE ESTUDIOS.-8 
las fases del hermanamiento. Estos han constituido el instrumento principal mediante el que el Consejo de Municipios y Regiones de Europa ha llegado a convertirse en una organización europeísta de masas con amplia presencia y participación popular (39).

Después de los primeros años, los hermanamientos han adoptado un nuevo enfoque a sus relaciones tradicionales: Aprovechando el espíritu de los acuerdos de Lomé los municipios europeos han programado, a inicitiva del CCRE, acciones conjuntas en favor del Tercer Mundo (40).

Por otra parte el CCRE organiza periódicamente congresos que reúnen a los municipios hermanados europeos con el objeto de intercambiar ideas así como de dar un impulso nuevo a los hermanamientos antiguos y modernos. El último de ellos (el V) se celebró, en Burdeos en marzo de 1987, con la participación de cerca de mil electos locales y regionales de los Estados miembros de la Comunidad Europea, Austria y Suiza. Tanto las resoluciones adoptadas (41) como la declaración final constituyen una auténtica manifestación de voluntad y espíritu europeísta, al afirmar que el movimiento de hermanamiento representa «la fuerza popular más movilizada y movilizable en favor de la construcción europea», así como un instrumento de acercamiento y de «comprensión universal entre los pueblos» que debe servir a «la causa de la Unión Europea» y a la consecución de la paz en el mundo. La Declaración considera, por otra parte, que, una vez conseguido el objetivo de la reconciliación entre los europeos, y que aunque la Federación de Estados Europeos esté todavia lejos de ser alcanzada, corresponde a los municipios hermanados ejercer el papel de «vanguardia en la lucha por la Europa de los ciudadanos y de preparar activamente la consecución de una verdadera ciudadanía europea». A tal efecto, tras recordar que la consecución del Gran Mercado Unico no es más que un objetivo parcial, reafirman «su fidelidad al objetivo del CCRE de tender hacia una Unión Europea dotada de un verdadero poder ejecutivo (Gobierno) y cuyos poderes legislativos serían ejercidos por un sistema bicameral constituido:

(39) Este carácter presentó ya el inicio del movimiento de los hermanamientos: en marzo de 1952, y tan sólo un año después de la constitución del Consejo de Municipios de Europa, el hermanamiento entre Metz y Luxemburgo supuso un gran acontecimiento popular, así como un hito importante en la fase de reconciliación europea de la posguerra.

(40) En este sentido cabe señalar que el CCRE ha propuesto a los municipios, departamentos y regiones de Europa la participación en el programa «Solidaridad-Agua» con el fin de aprovechar más racionalmente los recursos de agua de los paises del Tercer Mundo.

(41) Estas se refieren a «La organización de un hermanamiento y los problemas de financiación», «Los hermanamientos y la cooperación», «La promoción de los hermanamientos» y «Los municipios hermanados en el año europeo del medio ambiente». 
- Por una Asamblea de los pueblos (Parlamento europeo) elegida por sufragio universal directo.

- Por una Cámara Alta, nacida del actual Consejo de Ministros, que representaría a los Estados (42).

B) La Asociación de Regiones Fronterizas Europeas (ARFE) tiene como función primordial el fomentar la cooperación transfronteriza en el marco de las buenas relaciones de vecindad y del derecho internacional de la cooperación. El fenómeno de la cooperación transfronteriza que tiene hondas raíces en Europa (43), ha experimentado en los últimos años un gran auge debido principalmente a la obra del Consejo de Europa, aunque también OCDE y la Comunidad Europea (44) han tomado posiciones al respecto.

El Convenio-Marco sobre la cooperación transfronteriza adoptado por el Consejo de Europa el 21 de mayo de 1980, y en vigor desde 1981 (45) constituye el hito principal alcanzado en la materia hasta la fecha. En su artículo 2 se define como cooperación transfronteriza la concertación o coordinación tendente a desarrollar las relaciones de vecindad entre colectividades o autoridades territoriales de dos o más Estados Partes, así como la conclusión de acuerdos para el logro de esta finalidad (46).

La cooperación transfronteriza, objetivo esencial de la ARFE, se lleva a cabo en varios niveles, a la vez complementarios: a nivel interestatal o intergubernamental, y a nivel infraestatal, es decir, regional y local. Supuestos ambos reconocidos por el Convenio-Marco en sus artículos 2 y 3 . El segundo nivel de cooperación presenta para el profesor Bernad (47) las notas características de la espontaneidad y diversidad, la flexibilidad y la ausencia de formalismo que se

(42) Déclaration finale du V Congrés des Communes européennes jumelées, Bourdeaux, 20-21 mars 1987. Conseil des Communes et Regions d'Europe, Résolutions, págs. 1 y 2.

(43) Es de destacar que ya en la década de los cincuenta, y por iniciativa pública en unas ocasiones y privada en otras, se inició una creciente cooperación entre las regiones fronterizas de Francia, Alemania y Suiza.

(44) En este sentido cabe destacar que la Comunidad Económica Europea adoptó en 1985 el programa CORINE (CEE, JOL-176, de 16 de julio de 1985), que constituye un ejemplo de cooperación transfronteriza de aplicación de la política comunitaria medioambiental.

(45) España, que firmó dicho Convenio en octubre de 1986, todavia no lo ha ratificado. El motivo de esta actitud radica, según unas declaraciones manifestadas por el ministro de Administraciones Públicas del Gobierno español en la IV Conferencia de Regiones Fronterizas celebrada en Zaragoza en marzo de 1987, en que deben establecerse previamente acuerdos interestatales que garanticen la eficacia y den un mayor sentido a dicho Convenio-Marco. Sobre el proceso de elaboración, alcance y contenido del convenio vid DECAUX, E.: «La convention-cadre européenne sur la coopération transfrontalière des collectivités on des autorités locales», RGDIP, t. $88,1984 / 3$, en especial págs. 580-615.

(46) Es significativo señalar que en dicha Convención se incluye un anexo con modelos y esquemas de acuerdo con estatutos y de contratos en materia de cooperación transfronteriza entre colectividades 0 autoridades territoriales.

(47) Bernad Alvarez de Eulate, M.: «La Comunidad de trabajo de los Pirineos en el rntexto europeo de cooperación transfronterizas, en $R E D I, 1984-2$, pp. 473 y 474. 
manifiestan, entre otras formas, en la colaboración entre entidades territoriales no equivalentes en el ámbito estructural y competencial.

Cabe afirmar no obstante que el tema de la cooperación entre regiones y municipios fronterizos, aunque se lleve a cabo a niveles «infraestatales», no escapa del campo del derecho internacional. Como ha afirmado Dupuy: «On aurait cependant tort de croire que le droit international doit pour autant se désintéresser de ces relations "à bas niveau". La diversité des problèmes juridiques qu'elles continuet de poser... incite au contraire à penser que l'action internationale des Etats pour faciliter cette coopération devrat aboutir à la conclusion de conventions cadres, destinées à harmoniser les procédures et à faciliter les contacts entre ces entités...» (48).

Este «interés» del Derecho Internacional por el tema de la cooperación transfronteriza se debe además del indiscutible elemento internacional que presenta el fenómeno, a la firme actitud de varias organizaciones internacionales, principalmente europeas, que contribuyen a su promoción e institucionalización, y al hecho de que la cooperación transfronteriza repercute directamente en la cooperación internacional, contribuyendo al mismo tiempo a la construcción europea. Así lo ha considerado el Consejo de Europa al incluir en el Tercer Plan a Medio Plazo (1987-1991) la intensificación de la cooperación entre regiones y municipios fronterizos (49).

En el ámbito pirenaico, hay que destacar que aprovechando la experiencia de la Conferencia del Arco Alpino (50) y de la Comunidad de Trabajo de los Länder y Regiones de los Alpes Orientales (51) se celebró la Conferencia de las Regiones Pirenaicas (52) en la que se aprobó la Declaración de Jaca. En ella vuelve a ponerse de relieve la estrecha conexión existente entre la cooperación transfronteriza y la Unión europea:

«L'Union européenne et les déclarations officielles à̀ son sujet n'ont aucun sens si elles ne s'acompagnent d'une coopération franche et loyale aux frontiéres interieures de l'Europe. L'engagement d'un etat dans l'Union se mesure à l'overture de sa coopération à la frontiére. L'esprit de cette coopération, son étendue, son efficacité, sont étroitement fronction du degré d'engagement à fons les niveaux

(48) DupuY, P. M.: La coopération régionale transfrontalière..., op. cit., p. 853.

(49) Troisième Plan à Moyen Terme 1987-1991. L'Europe des démocraties: Humanisme, diversité, universalité. Strasbourg. Décembre 1986, pp. 70 y 71 .

(50) Celebrada en Lugano en 1978.

(51) Fundada el 20 de noviembre de 1978 en Venecia. Está compuesta por 14 miembros pertenecientes a cinco Estados con sistemas sociales y políticos diferentes: Italia, Yugoslavia, Austria, República Federal de Alemania y Hungria. El conjunto de la Comunidad abarca un territorio de 270.000 kilómetros cuadrados en el que viven unos 37 millones de habitantes.

(52) Celebrada en Jaca y Oloron-Ste. Marie del 8 al 10 de junio de 1982. 
concernés et particulièrement au niveau des populations frontalières et de leurs collectivités» (53).

La Comunidad de Trabajo de los Pirineos fue constituida en Burdeos en 1983 por los ocho firmantes de la Declaración, con objeto de intercambiar informaciones, discutir cuestiones técnicas y buscar soluciones coordinadas en los temas de transportes y comunicaciones, energía, agricultura, economía hidráulica, turismo, medio ambiente, urbanismo y patrimonio cultural, según se establece en el artículo 2 de su Carta constitutiva.

La Comunidad (54) de la que son miembros las Comunidades autónomas españolas de Aragón, Cataluña, Euzkadi y Navarrra, las Regiones francesas de Aquitania, Languedoc-Roussillon y MidiPyrénées, así como Andorra, según su artículo 1, presenta por otra parte la siguiente estructura orgánica:

- El Consejo de la Comunidad, que según el artículo 5 se compone de siete representantes por cada Miembro, entre los que se recomienda la presencia del Presidente de cada una de las colectividades fronterizas subregionales (departamentos, provincias $u$ otras).

- La Presidencia que la asume por turno y en orden alfabético de cada Miembro en la persona de su Presidente, según determina el artículo 4. Actualmente ostenta la Presidencia la Comunidad Autónoma de Cataluña en la persona del Presidente de la Generalitat (55).

- El Secretariado, que asume sus tareas bajo la responsabilidad del Presidente (art. 7), y que es designado por acuerdo del Consejo de la Comunidad con ocasión de cada cambio de Presidencia.

- Los Organismos Técnicos (art. 7, párr. 2) que podrán crearse para facilitar los trabajos de la Comunidad, y las Comisiones permanentes consultivas que pueden crearse entre representantes de colectividades territoriales subregionales (art. 3).

Según el artículo 8, los documentos de trabajo se preparan en lengua española y francesa, pero las demás lenguas habladas en los Pirineos podrán utilizarse igualmente como lenguas de trabajo (56).

(53) Déclaration finale de la Conférence des Régions Pyrénéennes. Jaca-Oloron 8-10 juin 1982. Conseil de l'Europe. Assemblée Parlamentaire. Conférence des Pouvoirs Locaux et Régionaux de l'Europe.

(54) Que se constituyó por la firma del acuerdo en la ciudad francesa de Pau, los dias 4 y 5 de noviembre de 1983, tiene su sede permanente en la ciudad oscense de Jaca.

(55) La Comunidad de Trabajo de los Pirineos celebró su quinta sesión plenaria en la localidad de Sort (Lérida) durante los dias 18 y 19 de febrero de 1988, siendo presidida por el Presidente de la Generalidad de Catalunya, Jordi Pujol, actual Presidente de la Comunidad. Los trabajos desarrollados versaron sobre la problemática especifica de las comarcas de montaña, centrándose en el tema de comunicaciones, turismo, cultura, economía de montaña, cartografia y medio ambiente.

(56) El propio texto del Acuerdo de la Comunidad de Trabajo de los Pirineos fue adoptado en catalán, vasco, aranés y fabla aragonesa, además de castellano y catalán. 
La Asociación de Regiones Fronterizas ha contribuido activamente a la organización de la IV Conferencia europea de Regiones Fronterizas, celebrada recientemente en la ciudad de Zaragoza, en la que ha presentado varios informes sobre problemas específicos que se plantean en tales regiones.

C) La Conferencia de Regiones Periféricas Marítimas de LA Comunidad Europea (CRPM) fue fundada en 1973 en SaintMalo (Bretaña francesa) por los delegados representantes de 23 Regiones Periféricas Maritimas.

Según el artículo 1 de su Carta constitutiva (57) la Conferencia está formada por la reunión de los delegados mandatarios de las instancias representativas de las Regiones que hayan aprobado la Resolución común de 23 de junio de 1973, que fija su objeto. En este sentido, las Regiones de los Estados Miembros de la Comunidad Europea actúan a título de Miembros de pleno derecho, aceptándose expresamente la posibilidad de que las Regiones de Estados candidatos a la Comunidad (58) actúen a título de Miembros-asociados con los mismos derechos que aquéllas, así como que otras Regiones lo hagan únicamente como observadores, con voz pero sin voto (59).

La Conferencia de Regiones Periféricas Marítimas de la Comunidad Europea agrupa en la actualidad más de 65 regiones, correspondientes a nueve Estados diferentes de la Comunidad Europea y que representan una población de más de 85 millones de habitantes. De este modo, la Conferencia constituye la prefiguración de un nuevo «nivel regional» del que adolecía la construcción europea entre los Estados y los Poderes locales.

El fin último de la Conferencia es conseguir para las Regiones un papel activo en la construcción de Europa, a través de una acción solidaria destinada al acercamiento entre las poblaciones más alejadas y aisladas del continente, y a la puesta en práctica de una estrategia de reequilibrio entre el centro industrializado y la periferia, en general menos desarrollada. En este sentido, promueve la defensa de ciertas potencialidades regionales ligadas a la mar y al litoral, fomentando al mismo tiempo un esfuerzo de adaptación y renovación interna basado en el estudio e intercambio de información, ideas y experiencias, así

(57) Adoptada por la Conferencia plenaria en Inverness el 5 de mayo de 1977, y modificada por el Comité Permanente el 8 de noviembre de 1979, en Santiago de Compostela; por la Conferencia Plenaria el 8 de octubre de 1981, en Chania; por la Conferencia Permanente el 29 de septiembre de 1982, en Porto, y el 23 de noviembre de 1985, en Estrasburgo.

(58) Como ocurría con ciertas regiones de España y Portugal antes de su adhesión a la Comunidad Económica Europea. En 1983, las regiones que actuaban en la Conferencia como miembros asociados eran las siguientes: Galicia, Andalucia, Canarias y Baleares de España, y Norte, Centro, Lisboa y Vale do Tejo, Algarve, Açores y Madeira de Portugal.

(59) En 1983 tenian esta consideración las siguientes Comunidades Autónomas españolas: Asturias, Cantabria, Pais Vasco, Cataluña, Valencia y Murcia. 
como en la cooperación activa entre las Instituciones y Organizaciones Europeas en los diferentes niveles.

Según el artículo 4 de sus Estatutos, la Conferencia se estructura internamente en dos niveles distintos:

a) El deliberativo, que agrupa al conjunto de las Regiones en la adopción de decisiones comunes:

- La Conferencia Plenaria, formada por cinco delegados por cada Región, se reúne cada cuatro años para la toma de decisiones de carácter plurianual.

- La Conferencia Permanente, formada por dos delegados por Región, se reúne al menos una vez al año para adoptar las decisiones de alcance anual, en especial en materia presupuestaria.

b) El ejecutivo, que comprende tres órganos diferentes:

- El Buró Político, compuesto por nueve miembros elegidos por dos años y competente para nombrar un Presidente, que está capacitado para actuar como representante oficial y Director de la CRPM, y a dos Vicepresidentes.

- Los Delegados Ejecutivos, designados anualmente por la Conférencia con el fin de canalizar los objetivos programados, para lo cual puede hacerse asistir por expertos y por un grupo de trabajo técnico.

- El Secretario General designado por la Conferencia y encargado de su funcionamiento con la asistencia de un grupo de funcionarios que coordinan las relaciones con los diferentes países.

Las actividades de la Conferencia se dirigen principalmente en tres sentidos:

1. La promoción de los asuntos sociales (educación, cultura ...) de los intercambios (jóvenes trabajadores-empresas) y de las actividades endógenas (Agricultura, Pesca, Tecnología, Turismo ...).

2. Las intervenciones en la Política Regional, a través de acciones comunes para el reequilibrio de Europa, y en los transportes, a través de estudios y proyectos para aproximar las regiones periféricas europeas.

Asimismo promueve acciones específicas en la zona del Mediterráneo y en favor de las islas, a través de la Comisión de Regiones Insulares (60) y para la protección y desarrollo del Litoral. En este

(60) La Comisión de las Islas instituida en el seno de la CRPM data de 1979 y su finalidad esencial radica en estudiar posibles soluciones a los problemas de las regiones insulares en un intento de adaptación de dichas regiones al mercádo común. En la reunión de la Comisión celebrada en Douglas (isla de Man), durante el mes de mayo de 1987, se adoptaron diversas resoluciones encaminadas a la consecución de tales objetivos. 
sentido, la Conferencia adoptó en 1981 la Carta Europea del Litoral (61) en la que se establecen objetivos detallados que van desde el desarrollo de la economía litoral, hasta la prevención de riesgos y el fomento de la investigación y la cooperación transfronteriza, para lo cual propone un programa de acción concreto a cuatro niveles diferentes: europeo, estatal, regional y local.

3. La cooperación con las Instituciones Europeas, con las Organizaciones de Poderes Locales (CCRE, IULA, FMVJ) y con otras Organizaciones Regionales.

La Conferencia de Regiones Periféricas Marítimas de la Comunidad Europea goza desde 1978 del Estatuto Consultivo Oficial del Consejo de Europa.

D) El Consejo de las Regiones de Europa (CRE) fue creado en 1985 sobre la idea de que los principios de la descentralización, el regionalismo y el federalismo son beneficiosos para la tarea de la construcción de Europa desde el momento que pueden canalizar nuevas fuerzas e ideas en el proceso de unidad europea. En este sentido, el artículo 2 de sus Estatutos establece como objetivos de la Asociación el «organizar el diálogo, la concertación, el estudio y la acción comunes de las Regiones pertenecientes a los Países-Miembros de la Comunidad Europea y del Consejo de Europa, en el respeto a los Tratados y Constituciones de los diferentes Estados»; así como el de ureforzar la representación de las Regiones en las Instituciones Europeas, y facilitar su participación en la construcción de Europa ...».

Para el logro de sus fines, el Consejo de las Regiones de Europa, del que son miembros titulares las Regiones pertenecientes a los Países Miembros de la Comunidad Europea y del Consejo de Europa (art. 3), dispone de los siguientes órganos: La Asamblea General, compuesta de las delegaciones formalmente designadas por los órganos representativos de las Regiones (art. 5); el Comité Permanente que administra la Asociación y se compone de un mínimo de 20 miembros y de un máximo de 50 (art. 6); el Buró, formado por un máximo de 15 miembros entre los que se encuentran el Presidente y los Vicepresidentes (art. 7).

El papel de sensibilización ejercido por las diferentes Organizaciones de Poderes Locales, en particular por el Consejo de los Municipios de Europa creado en 1951, así como la formación de organizaciones regionales europeas, a partir de la década de los 70 , trajo como consecuencia, más o menos mediata, la consulta progresiva a los poderes locales y regionales por parte de las instituciones comunita-

(61) Adoptada en Creta tras tres años de preparación. Fue votada por el Parlamento Europeo el 18 de junio de 1982. 
rias, en especial la Comisión y el Parlamento, asi como la institución del FEDER en 1975. La creación del Consejo de las Regiones de Europa (CRE) debe inscribirse igualmente en este proceso evolutivo de la integración de los problemas regionales.

La creación del Consejo Consultivo de las Colectividades Regionales dentro de la Comisión Europea abre una vía hacia la normalización de las relaciones entre las Organizaciones de Poderes Locales y Regionales (61 bis), así como hacia la institucionalización del papel de las Regiones en el seno de la Comunidad Europea, como consecuencia del Acta Unica.

Aun admitiendo, desde un punto de vista jurídico, que las Regiones no pueden interferir en los procesos de decisión de los órganos de poder comunitarios, las perspectivas de su contribución positiva son múltiples y amplias, ya sea de una forma colectiva o individual. Desde el punto de vista de la contribución colectiva, cabe mencionar las posibilidades de consulta, en especial a través del recientemente creado Consejo Consultivo (62), así como la participación en los trabajos y estudios multirregionales o el apoyo a la aplicación de los programas comunitarios. Desde la óptica de la contribución individual hay que destacar que el nivel regional es el más apropiado para la integración de políticas complejas y para la movilización de las potencialidades de desarrollo.

En sus relaciones con las instituciones comunitarias es necesario que las Regiones potencien cada vez más su papel de intermediario. Las Regiones pueden, a través de esta via, participar en las nuevas políticas comunitarias, en particular las tecnológicas, utilizando sus contactos transnacionales cooperando con las empresas radicadas en su territorio a controlar colaboradores en otros Estados europeos. Por otra parte, es conveniente que se concedan ayudas comunitarias a la cooperación interregional, en el marco de la reforma de los fondos estructurales.

En el desarrollo de los Segundos Estados Generales de las Regiones de Europa, promovidos por el CRE y celebrados en Bruselas durante los días 19 y 20 de noviembre de 1987, se plantearon por diversas delegaciones las siguientes propuestas:

- Que el Consejo de las Regiones de Europa apoyara la creación de un «organismo de servicio europeo» para la cooperación de las

(61 bis) En este sentido, cabe señalar que el art. 13 de los Estatutos del CRE establece la vía de la cooperación entre el CRE y el Centro Europeo de Desarrollo Regional (CEDRE) por medio de un protocolo cuyo fin es prestar asistencia a las Regiones y Organizaciones Regionales Europeas en materias como investigación, asesoramiento, ayudas al desarollo, etc.

(62) Vid. en este sentido la ponencia presentada por Georges PIERRET, Secretario General del CRE, titulada: «La creación de un Consejo Consultivo de las Colectividades Regionales y Locales dentro de la Comisión Europeas. Consejo de las Regiones de Europa. Segundos Estados Generales de las Regiones de Europa. Tema III. 20 de noviembre de 1987. 
diferentes entidades territoriales de Europa. Dicho organismo debería ser creado conjuntamente por el Consejo de Europa y la Comunidad Europea, debiendo garantizar su cooperación con las organizaciones que se ocupan de la cooperación transfronteriza (63).

- Que el Consejo de las Regiones de Europa reclamara una mayor intensificación en la colaboración entre el Consejo de Europa y la Comunidad Europea con el objeto de no duplicar esfuerzos, en particular en el campo de la técnica, así como para evitar, a partir de la entrada en vigor del Acta Unica Europea, un nuevo desequilibrio entre regiones fronterizas intracomunitarias y extracomunitarias, por un lado, y entre regiones centrales y periféricas, por otro (64).

- La propuesta de conseguir una segunda cámara en el Parlamento Europeo representativa de las Regiones estuvo también presente en muchas intervenciones (65). El cambio de nombre del Consejo de las Regiones de Europa por el de Asamblea de las Regiones de Europa fue defendido, junto a otros argumentos, como una aproximación a esta idea.

\section{De ÁMBITo MUNDiAL}

A) La Unión Internacional de Ciudades y Poderes LocaLES (IULA) constituye la más importante asociación internacional de poderes locales de ámbito mundial. Fundada en la ciudad de Gand (Bélgica), en 1913, la Unión Internacional de Ciudades y Poderes Locales, está regulada por la ley belga de 25 de octubre de 1919, modificada por la ley de 6 de diciembre de 1954 (art. 1 de sus Estatutos). La asociación trabaja en pro de la mejora de la administración local, así como para la promoción de la cooperación y de la concertación entre las colectividades locales del mundo entero. Actualmente los miembros de la IULA se reparten entre más de 70 paises diferentes, habiéndose abierto recientemente secciones regionales en América Latina y Africa con el fin de promover los intereses de la administración local en aquellas zonas geográficas.

Los objetivos de la asociación giran, según el artículo 3 de sus Estatutos, en torno a la vida local, eje y razón de ser la misma: promoción de la autonomía local, contribución a la mejora de la administración local, estudio de las cuestiones de interés para la vida

(63) Vid. en este sentido la ponencia presentada por RoBert RUDER, Secretario de Estado del Land Baden-Württemberg, titulada: «La cooperación transfronteriza intracomunitaria y en las fronteras entre la CEE y el AELE» Consejo de las Regiones de Europa. Segundos Estados Generales de las Regiones de Europa. Tema II. 19 de noviembre de 1987. Pág. 2.

(64) Ibid. pág. 3.

(65) Vid. en este sentido, la ponencia presentada por Hinz-Peter Volkert, Presidente del Landtag de Renania-Palatinado sobre: «La aportación de los Lảnder a la Europa de las Regiones». Consejo de las Regiones de Europa. Segundos Estados Generales de las Regiones de Europa. Tema IV. 20 de noviembre de 1987, pág. 2. 
y actividades de las administraciones locales y el bienestar de sus ciudadanos y la promoción de la participación de los mismos en aquéllas. Para la consecución de los fines propuestos, el propio art. 13 proclama una exquisita imparcialidad politica, asi como la remisión a la Declaración Universal de Derechos Humanos, a la que califica como «directiva de la asociación».

Con el fin de alcanzar sus objetivos, IULA ha establecido un programa de actividades permanentes, institucionalizadas en el art. 4 de sus Estatutos. En este sentido, la asociación organiza cada dos años un congreso mundial en el que se reúnen los representantes de los poderes locales y organismos semejantes para discutir cuestiones referidas a la administración local y a la defensa de su autonomía. Con carácter igualmente bianual, la asociación organiza un «Fórum de Grandes Ciudades» consagrado a los problemas específicos de las regiones metropolitanas del mundo, asi como seminarios regionales y conferencias de carácter más restringido sobre temas puntuales y de actualidad que interesen a la administración local. IULA mantiene asimismo una oficina permanente con el objeto de reunir, estudiar y difundir toda la información existente sobre la administración local.

Una de las actividades más interesantes de la asociación radica en el establecimiento y desarrollo de relaciones internacionales entre administraciones locales, asi como la cooperación con otras organizaciones internacionales gubernamentales o no gubernamentales en temas de interés común. En este sentido, cabe destacar que el Comité de asuntos europeos (66) se ocupa de las relaciones de IULA con el Consejo de Europa y con la Comunidad Económica Europea. Asimismo la asociación, en colaboración con el CCRE (67) asegura el funcionamiento del Comité Consultivo de las Instituciones Locales y Regionales, creado en el seno de la CEE a instancias del CCRE y de IULA con el objeto de estudiar los problemas concretos de la puesta en marcha de la politica regional y de coordinar en lo posible las políticas comunes entre las colectividades locales y regionales de los Estados miembros.

Por otra parte, es necesario señalar que IULA goza de estatuto consultivo en las Naciones Unidas, en varios organismos especializa-

(66) A través del mismo las relaciones de trabajo entre IULA y las instituciones de la Comunidad Europea se han intensificado últimamente: Asi cabe destacar, entre otras, el Coloquio de Rotterdam sobre los servicios municipales para los impedidos fisicos, la reunión mantenida en Bruselas en octubre de 1986, sobre el medio ambiente, con los representantes de la Comisión Europea, asi como el apoyo financiero de la CEE al «magazine» de la Asociación «Emploi Local». Vid. en este sentido «Administration locale», IULA Nouvelles, vol. 8, núm. 3, marzo [y87. p. 1.

(67) Por lo que respecta a las relaciones entre IULA y CCRE, cabe señalar que el Comité Ejecutivo de IULA adoptó, en mayo de 1987, el documento «La Voie de l'Avenin», que fija los objetivos de la asociación para los próximos cinco años, y contiene una recomendación en favor de intensificar las relaciones con el CCRE con el objeto de una eventual fusión. Vid. en ese sentido «Administration locale», IULA Nouvelles, vol. 8, núm. 6, junio 1987, p. 1. 
dos, así como en el Consejo de Europa. Asimismo la asociación ostenta la Secretaría del Consejo Internacional Hábitat (Comité de la ONG sobre establecimientos humanos) (68) y mantiene relaciones estrechas con las Comunidades Europeas, organizando actividades comunes no sólo con éstas sino también con numerosas organizaciones de servicios públicos con diferentes cometidos e intereses.

En relación con los miembros de la asociación, los Estatutos establecen una diferenciación entre miembros activos: asociaciones o secciones nacionales de poderes locales y administraciones locales individuales (art. 9); adheridos: personas morales y fisicas relacionadas o interesadas en la administración local (art. 15); extraordinarios: personas morales diferentes a las administraciones locales o regionales (art. 19), y honorarios: personas que hayan prestado servicios especiales a la asociación o al desarrollo de las relaciones municipales internacionales en general (art. 21).

Por lo que se refiere a su estructura interna IULA se compone de tres órganos diferentes:

1) El Consejo, formado por todos los miembros activos (art. 32) y con competencias para la admisión de miembros (arts. 13, 14 y 18), aprobación del presupuesto, elección del Presidente de la Asociación, fijación del programa de actividades y revisión de los estatutos (art. 34).

2) El Comité Ejecutivo, compuesto por el Presidente y de, al menos, 30 miembros (art. 50) de nacionalidad diferente (art. 51) con competencias fundamentalmente de gestión económica (arts. 62 a 65).

3) El Presidente (art. 79), y

4) El Secretario General que constituye el órgano ejecutivo de la asociación (art. 81), nombrado y revocado por el Comité Ejecutivo (art. 81) y con competencias para asegurar la gestión de la asociación, ejecutar las resoluciones del Consejo y del Comité Consultivo (art. 84) y para presentar al Comité Ejecutivo con carácter anual un estado detallado de cuentas sobre la situación financiera de la asociación (art. 85).

Por último, cabe destacar igualmente la tarea llevada a cabo por IULA en favor de la autonomía local. En este sentido, el Congreso de la asociación celebrado en Río de Janeiro en 1985, adoptó la Declaración Universal de la Autonomía local, que fue incluida para

(68) En este sentido, cabe destacar que en abril de 1987 tuvieron lugar en Nairobi (Kenia) dos importantes encuentros: La X Asamblea Anual de la Comisión de las Naciones Unidas para los Establecimientos Humanos; y el Fórum Mundial de las ONG, organizado por el Consejo Internacional Hábitat. Las decisiones adoptadas en ambos foros hacen referencia a los problemas relacionados con la vivienda y el hábitat, así como sus posibles soluciones en el seno de las administraciones locales. Ibid. p. 3. 
su examen en el orden del dia de la primera asamblea del ECOSOC de 1987 (69).

B) Estrechamente relacionado con el CCRE se encuentra la Unión INTERNACIONAL DE AlCALDEs (UIM), que se constituye como una asociación municipalista que agrupa a los alcaldes electos a título personal. Sus actividades son programadas con carácter anual por el Comité Administrativo Internacional (70).

C) La Federación Mundial de Ciudades Unidas (FMVJ) fue fundada en Aix les Bains (Francia) en 1957 por iniciativa de la asociación francesa «El Mundo Bilingüe» (71) con el lema «Cooperación sin discriminación entre los pueblos del Mundo».

La Federación se constituye en la actualidad como una organización internacional no gubernamental con sede en París (72) de carácter municipalista y de ámbito mundial que agrupa ciudades a título particular. Implantada al Este y al Oeste, al Norte y al Sur, la Federación reúne directamente unas mil doscientas colectividades locales y regionales repartidas en más de 60 Estados (73), manteniendo relaciones con otras 3.000 a través de las asociaciones nacionales y regionales de municipios adheridos a las «Ciudades Unidas» (74) en calidad de miembros asociados.

Los miembros de la FMVJ son, en general, corporaciones territoriales infraestatales: ciudades, municipios, regiones (75). Sin embargo, las asociaciones, las uniones de empresas, los servicios gubernamentales o intergubernamentales, los centros de enseñanza, universidades, etcétera, pueden integrarse a la Federación como miembros «asocia-

(69) Vid. en este sentido, «Administration locale» IULA, Nouvelles, vol, 8. núm. 4, abril 1987, página 5 .

(70) Sirva como muestra del alcance de las actividades de la UIM, el calendario adoptado por el Comité Administrativo para 1987: Encuentro de alcaldes alemanes en Normandia sobre el tema: "Tratamiento de la polución en el aire, en el agua y en la tierra»; Congreso estatutario bianual y Primer Simpósium de las ciudades hermanadas franco-alemanas del 29 de septiembre al 1 de octubre de 1987 en Niza. Vid. en este sentido, «Le jornal del Communes et Regions d'Europe», CCRE, núm. 5 , febrero 1987 , p. 21.

(71) El «Mundo Bilingúe» fue creado en 1951 por un grupo de antiguos miembros de la Resistencia de la Segunda Guerra Mundial, que agrupaba a periodistas, profesores y parlamentarios, principalmente.

(72) Lo que determina que la Organización se rija por las leyes francesas sobre asociaciones. En 1957, fue reconocida por el Ministerio del Interior y a partir de 1967 disfruta del apoyo diplomático y financiero del Gobierno francés, gracias a una decisión del general De Gaulle.

(73) Entre los que se encuentra España. El Comité Español de Ciudades Unidas fue creado el 28 de mayo de 1985 en el seno de la Federación Española de Municipios y Provincias. En este sentido, cabe destacar que el que fuera alcalde de Madrid, Profesor Enrique Tierno Galván fue presidente de la Federación Mundial de Ciudades Unidas.

(74) La expresión «Ciudades Unidas» se emplea con frecuencia por referencia al de «Naciones Unidas»).

(75) Por otra parte, se han constituido en el seno de la FMVJ asociaciones de ciudades situadas en una zona geográfica determinada, como la Unión de Ciudades del Mediterráneo, que promueve la lucha contra la polución del medio marino, la defensa de las riberas y del medio ambiente, los intercambios culturales y el conocimiento de las civilizaciones mediterráneas. 
dos», disponiendo también del derecho de voto en las asambleas generales.

El objeto esencial de la Federación radica en alentar y fomentar los contactos entre poblaciones de todos los Estados a partir del marco municipal o regional. Esta acción se lleva a cabo desde una concepción política universalista y humanística, con un espíritu de apertura y pluralismo sin discriminación por motivos de raza, clase, opinión politica, filosófica o religiosa.

La Federación Mundial de Ciudades Unidas orienta sus esfuerzos a completar la cooperación de Estado a Estado mediante acciones comunes entre los municipios y las regiones en base a los siguientes objetivos:

1. Promover la democracia local de participación favoreciendo la vida asociativa en el municipio y ofreciendo a los ciudadanos la posibilidad de participar en la vida internacional.

2. Desarrollar una educación cívica internacional en el respeto de las diferencias y el pluralismo, en la amistad y la solidaridad hacia todos los pueblos.

3. Crear las condiciones de una educación bilingüe precoz y generalizada, allí donde el desarrollo de las instituciones educativas lo permita.

4. Constituir una opinión mundial capaz de pesar en las decisiones de los gobiernos afirmando el derecho de las personas y de las colectividades a una función transnacional, independiente de los Estados y de los bloques políticos.

5. Comprometer las poblaciones en la realización de acciones concertadas.

- para la distensión y desarme;

- para la salvaguardia de los derecho humanos y de las libertades fundamentales;

- para la libre circulación de las personas, las ideas y la información;

- para el establecimiento de un Nuevo Orden Mundial tendente a reducir las desigualdades debidas a los insuficientes recursos materiales y tecnológicos, que reconocería entre los derechos del hombre el derecho al desarrollo económico y social;

- contra el racismo y toda otra forma de discriminación, en particular con respecto a las minorias y a las poblaciones de extranjeros;

- para la salvaguardia de la naturaleza y del medio ambiente.

Para el logro de los objetivos propuestos la FMVJ dispone esencialmente de dos medios de acción: a) El hermanamiento de ciudades en base a los principios de no discriminación, no injerencia 
y libre circulación de personas e información; y b) los intercambios multilaterales de ideas y experiencias que se extienden a la mayor parte de los sectores técnicos o culturales de la vida municipal: problemas educativos y sociales, sanidad, urbanismo, transportes y comunicaciones..., etc.

El funcionamiento de la Federación se articula sobre el principio de la democracia directa, mediante la adhesión individual de los municipios y corporaciones locales y regionales de todos los Estados, disponiendo cada uno de ellos de un voto inalienable en el seno de la Asamblea General que se reúne cada tres años. En el intervalo, el Consejo de la Presidencia que asume la conducción del movimiento y el Consejo Internacional formado por miembros de todos los Estados, celebran sesiones anuales.

El Consejo de Administración vigila la puesta en marcha de los programas y maneja los asuntos financieros y administrativos de la organización. Sus reuniones son trimestrales.

La Federación Mundial de Ciudades Unidas mantiene relaciones de cooperación con organismos internacionales (76) y goza de Estatuto consultivo ante la UNESCO (77), las Naciones Unidas (78) y el Consejo de Europa.

\section{LA CONFERENCIA DE PODERES LOCALES Y REGIONALES DE EUROPA (CPLRE)}

\section{Proceso de CREAción}

J. Chaban-Delmas, propone, el 30 de noviembre de 1951, conjuntamente con otros miembros de la Asamblea Parlamentaria del Consejo de Europa, la creación de una Comisión de Asuntos Locales y Regionales en base a la consideración de que «... los representantes de las colectividades locales, unidos por encima de las fronteras por sus preocupaciones comunes son los artesanos indispensables de una Europa unida y respetuosa de las diversidades y que su acción debe permitir una penetración profunda de la idea europea entre sus pueblos al mismo tiempo que el establecimiento de lazos intimos entre estos...».

(76) Asimismo contribuye directa o indirectamente al sostenimiento de la Agencia Económica de las Ciudades Unidas (Paris), que asesora a la organización en materia de ordenación del territorio; del Instituto Henri Jaquet para la difusión de información y formación de electos y funcionarios locales; del Centro Mundial de Información sobre la Educación Bilingüe (Aosta, Italia), que proporciona asistencia lingüistica para asegurar el respeto a las lenguas maternas y del Comité Mundial de Periodistas para las Ciudades Unidas.

(77) En 1968 la Conferencia General de la UNESCO, en su XV sesión votó una resolución en la que calificaba a la FMVJ como un instrumento que «moviliza las poblaciones de los municipios hacia la comprensión y la cooperación internacionales».

(78) En 1971 la Asamblea General de las Naciones Unidas, en su Resolución 2861 (XXVI) destacó «el valor de los hermanamientos como instrumentos de cooperación internacional». 
La propuesta consigue el suficiente eco en la propia Asamblea y permite que el 27 de septiembre de 1953 se constituya la Comisión compuesta de parlamentarios de Estados miembros con el compromiso de obtener para ella un estatuto permanente.

En 1955, el 14 de octubre, la Asamblea Parlamentaria opta por reunir anualmente una conferencia de representantes de organizaciones estatales de poderes locales de los Estados miembros del Consejo de Europa.

La denominación CEPL, Conferencia Europea de Poderes Locales, efectúa su primera sesión en enero de 1957 en Estrasburgo, con un número de miembros idéntico al que se componía entonces la Asamblea Parlamentaria.

Su presidente, F. Dehousse, remarcó: ... «por vez primera elegidos locales participan en tal condición en la construcción europea en el marco de una institución intergubernamental».

Pero no fue hasta el 13 de septiembre de 1961 (79) que el Comité de Ministros del Consejo de Europa concedió el estatuto permanente a la CEPL considerándola organismo estatutariamente consultivo y técnico en virtud de sus propias atribuciones (80).

En 1975, una resolución (81) motiva la reforma de su estatuto por la que adopta definitivamente el nombre de Conferencia de Poderes Locales y Regionales de Europa (CPLRE).

\section{Objetivos y COMposición de La CONFERENCiA}

Según la Carta aprobada, el objetivo principal de la CPLRE «es hacer conocer al Comité de Ministros y a la Asamblea Consultiva su opinión sobre las medidas susceptibles de repercutir en la existencia de las colectividades locales y regionales...» (82).

Para ello, «la CPLRE asegurará la participación de los poderes locales y regionales para la realización de los objetivos del Consejo de Europa...».

En consonancia, las delegaciones en la CPLRE forman hasta un total de 340 miembros, de los cuales, 170 son los titulares y otros 170 suplentes.

El total de los considerados como titulares, 170, coincide con el número de integrantes de la propia Asamblea del Consejo de Europa.

(79) Res (61) Comité Ministros del Consejo de Europa.

(80) Artículo 17 Estatuto Consejo de Europa. «El Comité de Ministros puede constituir, por los fines que juzge aconsejables, Comités o Comisiones de carácter consultivo o técnico.»

(81) Resolución (75) 4. Adoptada el 19 de febrero por el Comité de Ministros del Consejo de

(82) Artículo 1.a), Carta de la CPLRE. 
La elección nacional de cada delegación de representación se efectúa en base a:

1) Personas que disponen de un mandato -elegidos- en el seno de las colectividades regionales o locales.

2) Personas que poseen mandato de responsabilidad directa ante una asamblea local o regional o una asociación nacional de poderes locales o regionales (83).

Lo anterior, ha de ser contemplado teniéndose en cuenta, por parte de cada Estado:

1) Distribución geográfica equilibrada de los delegados en el territorio de cada Estado.

2) Representación equiparable de las diferentes categorias de colectividades territoriales ... (84).

La previsión de la Carta hace referencia a buscar una cierta «compensacion" entre las diferentes categorias: representantes de poderes locales (Ayuntamientos..., etc.) y representantes de podres regionales (Comunidades Autónomas, Länder, Cantones, regiones..., etcétera).

Los miembros así elegidos formarán parte de la Conferencia de Poderes Locales y Regionales de Europa, cuyo mandato abarca dos sesiones ordinarias, es decir, dos años, permaneciendo en tal función hasta la apertura de la sesión siguiente.

Además de los 170 miembros de pleno derecho y que representan a todos los Estados miembros del Consejo de Europa, existen otros que tienen la categoría de observadores. Tal es el caso de representantes de Israel, Finlandia y Yugoslavia, cuyos Estados aun no siendo parte del Consejo de Europa no por ello se ven privados de cierta concesión al acogerse al status citado y regulado.

Es importante señalar que prácticamente desde sus orígenes, la CPLRE ha mantenido relaciones con otras organizaciones que tienen el estatuto de observador en la Conferencia como:

1. El Consejo de los Municipios de Europa (CCE).

2. La Unión Internacional de las Ciudades y Poderes Locales (UIV/IULA).

3. Unión Internacional de Alcaldes (UIM).

Y más recientemente con:

1. La Asociación de las Regiones Fronterizas Europeas (ARFE/AGEG).

(83) Articulo 2.a), 4, Carta de la CPLRE.

(84) Articulo 2.b). Carta de la CPLRE.

REVISTA DE ESTUDIOS. -9 
2. La Conferencia Permanente de las Regiones Marítimas Periféricas de la CE (CRPM).

3. La Federación Mundial de Ciudades Hermanadas (FMVJ/UTO).

Todos los que disfrutan de tal status pueden hacer oír su voz, en determinados casos (85) aunque no disfrutan de voto.

Como se observa, la Conferencia se constituye como una verdadera Asamblea Europea de corte regional y local constituyendo el principal foro de temas que interesan al poder descentralizado de los Estados, careciendo, no obtante, de un verdadero poder legislativo a modo y semejanza de la Asamblea Consultiva del Consejo de Europa.

\section{FunCIONAMIENTO}

De acuerdo con el artículo 3.a) la CPLRE se reúne todos los años en sesión ordinaria. Para tal fin, notemos que las propuestas de la Comisión Permanente fijando fechas para la celebración de la sesión anual preceptiva habrán de ser sometidas al Comité de Ministros para su aprobación, después de la consulta con el presidente de la Asamblea Consultiva del Consejo de Europa.

Ya en 1955, antes de la constitución de la CPLRE, la Asamblea Consultiva del Consejo de Europa habia votado, aprobándola, una recomendación dirigida a los Gobiernos de los Estados miembros, relativa a la necesidad de tomar medidas para dar la oportunidad a los poderes locales de afrontar los nuevos desafios que suponian la constitución de la Comunidad Europea del Carbón y el Acero (CECA).

Durante la primera sesión de la CPLRE (Estrasburgo 12/14 de enero de 1957) se repite la recomendación citada anteriormente, remarcando el peso que los poderes locales y regionales europeos deben de tener en el espíritu y en la práctica de la construcción europea.

Entre otras decisiones que toma la CPLRE en su primera sesión cabe destacar la opinión sobre la defensa y el desarrollo de la autonomía local, opinión inspirada en la «Carta europea de las libertades municipales» (86).

La segunda reunión se efectúa en octubre de 1958, y la tercera en enero de 1960. Es a partir de entonces que las sesiones hasta 1976 se efectúan en forma bianual.

Desde la aceptación de los delegados del Comité de Ministros del Consejo de Europa, las sesiones tienen carácter anual iniciándose con

(85) Artículo 2 bis.c). Carta de la CPLRE.

(86) Versalles. 1953. Reunión de los Primeros Estados Generales de los Municipios de Europa. 
esta periodicidad a partir de la undécima sesión, realizada los días 26 al 28 de abril de 1976.

Las sesiones se desarrollan en la sede del Consejo de Europa en Estrasburgo, salvo decisión contraria tomada de común acuerdo entre el Comité de Ministros y la Comisión Permanente de la CPLRE (87).

\section{Organos de la CPLRE}

De acuerdo con el Reglamento Interno de la CPLRE (88) ésta se articula en base a una Presidencia, un Buró, una Comisión Permanente, un Secretariado, las Comisiones y un plenario reunido anualmente en Asamblea.

A) El Presidente.

Al inicio de cada sesión ordinaria en la que las delegaciones nacionales tienen que ser renovadas, el delegado de mayor edad asume provisionalmente la Presidencia hasta la elección de su titular.

La duración de su mandato presidencial es por un periodo de dos años, los mismos que disponen todos los miembros componentes de la CPLRE.

La Presidencia se completa con la elección de cuatro Vicepresidentes, elegidos también entre los Delegados que provienen de los Estados miembros y cuyo mandato es también por otros dos años.

Hay ciertos requisitos para optar a la elección como Presidente -escrutinio secreto- como la ineludible condición de haber sido presentada su candidatura por escrito y por un mínimo de tres Delegados efectivos.

En la práctica, la elección del Presidente es una acción consensuada entre las delegaciones nacionales que buscan ciertos equilibrios compensatorios y de relación de poder en el seno de la Conferencia. De esta forma se evita la aplicación del artículo 6.4 del Reglamento interno de la CPLRE, que prevé que si después de dos vueltas de escrutinio ningún candidato recoge la mayoria absoluta de los votos de los Delegados efectivos en la Conferencia, la elección pasaria a una tercera vuelta por mayoría de votos expresados.

En el caso de la elección de los Vicepresidentes, su calificación en Primero, Segundo, ..., etc., se produce de acuerdo con el número, de mayor a menor, de votos obtenidos.

Tanto en el caso del Presidente como en el de los Vicepresidentes, su reelección no es posible salvo en el caso de que la Conferencia se manifieste por mayoría de dos tercios de votos. El consenso, en este

(87) Artículo 3.b), Carta de la CPLRE.

(88) Adoptado 10 de junio de 1980 (resolución 114) modificado el 18 de octubre de 1983 (resolución 139). 
caso, es inevitable. Tras esta reelección no podrá optarse a nueva candidatura a la presidencia. También en la práctica, las formas, de hecho, que no de derecho, convierten al Presidente cesante en Vicepresidente efectivo por un período de dos años.

B) El Buró.

Formado por el Presidente y los cuatro Vicepresidentes, es el encargado de establecer los programas y los calendarios de las reuniones de las comisiones tras haber recibido las opiniones de los Presidentes de las comisiones interesadas (89).

En esta tesitura el Buró funciona como una verdadera dirección colegiada al recoger, e incluso recomendar, iniciativas que, a través de los Presidentes de las comisiones constituidas, forman la espina dorsal en el mantenimiento de las actividades de la CPLRE.

Las reuniones del Buró se realizan en el período anual entre sesiones y no forzosamente tienen lugar en la sede oficial de la CPLRE.

\section{C) La Comisión Permanente.}

Según el artículo 5.a) de la Carta, la Comisión Permanente es el órgano encargado de asegurar la continuidad de la acción de la CPLRE. A tal fin, puede, en caso de necesidad, actuar en nombre de la propia Conferencia.

Con tales atribuciones, la Comisión Permanente puede analizar los informes que le someten las comisiones, puede adoptar resoluciones y opiniones contenidas en los citados informes por mayoria de dos tercios de votos expresados, reuniendo, como mínimo, la mayoria de los propios miembros que la componen.

La Comisión Permanente agrupa al Presidente, a los cuatro Vicepresidentes, a los cuatro Presidentes de las Comisiones y a otros veintidós miembros de representantes de la CPLRE. Con ello, se pretende aglutinar en la Comisión la máxima representación de los Estados miembros.

El Presidente y los cuatro Vicepresidentes de la CPLRE son también Presidente y Vicepresidentes de la Comisión Permanente.

En este tema de la representación de sus nacionales en el seno de la Comisión Permanente, el artículo 30.7 del Reglamento Interno de la CPLRE define el que cada Estado tenga un representante en su seno aunque las delegaciones de Estados como Francia, RFA, Italia, Gran Bretaña, Turquía y España tienen el derecho de estar representados con dos miembros.

(89) Art. 5.b), Carta de la CPLRE. 


\section{D) Las Comisiones.}

Cada dos años, aparte de la renovación de la Comisión Permanente, se produce, al inicio de la sesión, la constitución de las cuatro siguientes comisiones especializadas: torio.

- Comisión de problemas regionales y de ordenación del terri-

- Comisión de estructuras y finanzas locales.

- Comisión del medio ambiente y de urbanismo.

- Comisión de asuntos culturales y sociales.

La composición de las comisiones anteriores, especializadas para ser más exactos, pueden alcanzar, en su número total, a un máximo de treinta personas como titulares y llegar a una misma cifra para los suplentes.

También la CPLRE tiene facultad, en virtud del artículo 4.a) de su Carta, para formar las comisiones «ad hoc» que estime necesarias y cuyo tiempo de formación -la duración- termina una vez acabado su informe en la Conferencia.

\section{E) El Secretariado.}

La CPLRE no posee un Secretariado propio. La gestión administrativa que comporta la conferencia está encomendada a personal de Secretariado del Consejo de Europa, el cual destina, dentro de las disponibilidades permisibiles de la CPLRE personal a su servicio.

Según el artículo 42 del Reglamento Interno de la CPLRE «los servicios de la CPLRE están dirigidos por el Secretario ejecutivo de la CPLRE, bajo la autoridad del Secretario General (del Consejo de Europa). El Secretario ejecutivo es responsable de la preparación de los trabajos y de la puesta en marcha de las decisiones de la conferencia y de sus órganos y rinde cuentas del cumplimiento de sus tareas al Presidente de la CPLRE».

\section{RELACIONES CON OTRAS INSTITUCIONES}

Independientemente de las obligadas relaciones de la CPLRE con los órganos del Consejo de Europa, Comité de Ministros y Asamblea Consultiva, la CPLRE disfruta de relaciones con otros organismos del propio Consejo y, en especial, con las Conferencias de Ministros Especializados que interesan, por su temática, a la esencia mínima de la razón de ser de la CPLRE.

Citemos, brevemente, con qué otros organismos del Consejo de Europa se mantienen relaciones:

1. Comité director para asuntos regionales y municipales (CDRM). 
2. Conferencia de Ministros europeos responsables de las colectividades locales.

3. Conferencia europea de Ministros responsables de habilitación del territorio (CEMAT).

4. Comité Director para la habilitación del territorio y el patrimonio arquitectónico (CDAT).

5. Comisión de habilitación del territorio y de poderes locales de la Asamblea Consultiva del Consejo de Europa.

La formación de las Comunidades Europeas es un hecho capital presente en todo instante en el discurrir de la propia CPLRE. La necesidad de contactos más estrechos no cesa de plantearse por parte de la Conferencia, la cual desea convertirse en un órgano consultivo comunitario.

Realmente, y en esta línea, los trabajos de la Conferencia, particularmente los que se refieren a la habilitación del territorio y los que implican política regional son inseparables de la construcción comunitaria.

La modificación de la Carta, en 1975, remarca aún más, si cabe, la aspiración de la Conferencia tendente a ser un nexo de unión entre el propio Consejo de Europa y la Comunidad Europea.

Contactos permanentes se producen entre la propia Conferencia y miembros de la Comisión de la CE. De hecho, la Conferencia, en su sesiones, acoge a miembros muy cualificados de la $\mathrm{CE}$.

Por otra parte, tengamos presente que el artículo 230 CEE dispone que «la Comunidad establece con el Consejo de Europa todas las cooperaciones útiles», mientras que el 238 CEE hace hincapié en que «la Comunidad puede concluir con ... una organización internacional acuerdos cuando una asociación caracterizada por derechos y obligaciones reciprocas, acciones comunes y procedimientos particulares».

\section{CONSIDERACIONES FINALES}

El texto de la Carta Europea de la Autonomía Local no califica de «atribuidas» las competencias, funciones y tareas propias de las Corporaciones Locales. El hecho de que se autorice este calificativo respecto de otras autoridades de nivel superior, supone que aquél parte del ureconocimiento» de los principios de la autonomía local.

El procedimiento de control previsto en la Carta presenta limitaciones en cuanto que el artículo 14 no puede considerarse como un mecanismo de garantía eficaz para la protección de la autonomía local. Seria deseable que, al igual que ha ocurrido con otros casos, aquél pudiera completarse por medio de un Protocolo adicional o instrumento anexo que reforzara la propia acción institucional de la CPLRE y las asociaciones en ella representadas. 
El asociacionismo internacional de poderes locales y regionales constituye un instrumento muy apropiado para la promoción de la democracia local de participación y de la cooperación internacional, favoreciendo al mismo tiempo el proceso de unidad europea.

La exclusiva representación de los municipios en el seno de dichas asociaciones internacionales, se ha complementado últimamente por la creciente afluencia de las regiones, ejercida a través de su representación en las mismas o de la creación de asociaciones internacionales exclusivamente regionales. Igualmente, se manifiesta en la constitución del Consejo Consultivo de las Colectividades Regionales dentro de la Comisión Europea que abre una via hacia la institucionalización del papel de las regiones en el seno de la Comunidad Europea.

Esta doble representatividad de los poderes locales y regionales en el Consejo de Europa, a través de la CPLRE, y en la Comisión Europea, a través del Consejo Consultivo, no debe en ningún caso constituir una competencia estéril sino una complementaridad creativa, en cuanto que la finalidad última radica en la adecuada representación de los intereses locales y regionales en ambas instituciones, lo que, al mismo tiempo, contribuye al proceso de construcción europea. 
REALA-1988, núm. 237. GALISONDA JORDA, ALBERT. LA AUTONOMIA LOCAL EN EL MARCO JU...

REALA-1988, núm. 237. GALISONDA JORDA, ALBERT. LA AUTONOMIA LOCAL EN EL MARCO JU... 
REALA-1988, núm. 237. GALISONDA JORDA, ALBERT. LA AUTONOMIA LOCAL EN EL MARCO JU...

\section{CRONICAS}

REALA-1988, núm. 237. GALISONDA JORDA, ALBERT. LA AUTONOMIA LOCAL EN EL MARCO JU... 
REALA-1988, núm. 237. GALISONDA JORDA, ALBERT. LA AUTONOMIA LOCAL EN EL MARCO JU...

REALA-1988, núm. 237. GALISONDA JORDA, ALBERT. LA AUTONOMIA LOCAL EN EL MARCO JU... 